\title{
BK Channels Mediate Synaptic Plasticity Underlying Habituation in Rats
}

\author{
Tariq Zaman, ${ }^{1}$ CCleusa De Oliveira, ${ }^{1}$ Mahabba Smoka, ${ }^{1}$ Chakravarthi Narla, ${ }^{2}$ Michael 0. Poulter, ${ }^{2}$ \\ and ${ }^{-S}$ Susanne Schmid ${ }^{1}$ \\ ${ }^{1}$ Anatomy and Cell Biology, Schulich School of Medicine and Dentistry, University of Western Ontario, London, Ontario N6A 5C1, Canada, and 2Physiology \\ and Pharmacology, and Molecular Medicine Research Group, Robarts Research Institute, Schulich School of Medicine and Dentistry, University of Western \\ Ontario, London, Ontario N6A 5C1, Canada
}

Habituation is a basic form of implicit learning and represents a sensory filter that is disrupted in autism, schizophrenia, and several other mental disorders. Despite extensive research in the past decades on habituation of startle and other escape responses, the underlying neural mechanisms are still not fully understood. There is evidence from previous studies indicating that BK channels might play a critical role in habituation. We here used a wide array of approaches to test this hypothesis. We show that BK channel activation and subsequent phosphorylation of these channels are essential for synaptic depression presumably underlying startle habituation in rats, using patchclamp recordings and voltage-sensitive dye imaging in slices. Furthermore, positive modulation of BK channels in vivo can enhance short-term habituation. Although results using different approaches do not always perfectly align, together they provide convincing evidence for a crucial role of BK channel phosphorylation in synaptic depression underlying short-term habituation of startle. We also show that this mechanism can be targeted to enhance short-term habituation and therefore to potentially ameliorate sensory filtering deficits associated with psychiatric disorders.

Key words: habituation; learning and memory; rat; sensory filtering; startle; synaptic depression

\section{Significance Statement}

Short-term habituation is the most fundamental form of implicit learning. Habituation also represents a filter for inundating sensory information, which is disrupted in autism, schizophrenia, and other psychiatric disorders. Habituation has been studied in different organisms and behavioral models and is thought to be caused by synaptic depression in respective pathways. The underlying molecular mechanisms, however, are poorly understood. We here identify, for the first time, a BK channel-dependent molecular synaptic mechanism leading to synaptic depression that is crucial for habituation, and we discuss the significance of our findings for potential treatments enhancing habituation.

\section{Introduction}

Habituation is a basic form of nonassociative, implicit learning defined by the decrease in behavioral response to repeated stimulation that is not caused by receptor adaptation or muscle fatigue (for review, see Rankin et al., 2009). Habituation, especially short-term habituation of escape responses and protective reflexes, has been studied extensively in different animal models

\footnotetext{
Received Nov. 30, 2016; revised March 17, 2017; accepted March 21, 2017.

Author contributions:S.S. designed research;T.Z., C.D., M.S., C.N., and M.O.P. performed research; T.Z., C.D., M.S., and S.S. analyzed data; T.Z. and S.S. wrote the paper.

This work was supported by Canadian Institutes of Health Research Operating Grant R4202A08. T.Z. was supported by Ontario Mental Health Foundation Postdoctoral Fellowship.

The authors declare no competing financial interests.

Correspondence should be addressed to Dr. Susanne Schmid, Anatomy and Cell Biology, Schulich School of Medicine and Dentistry, University of Western Ontario, London, Ontario N6G 1R3, Canada. E-mail: Susanne.Schmid@schulich.uwo.ca. DOI:10.1523/JNEUROSCI.3699-16.2017

Copyright $\odot 2017$ the authors $\quad 0270-6474 / 17 / 374540-12 \$ 15.00 / 0$
}

ranging from Caenorhabditis elegans, Aplysia, Drosophila, and other invertebrates to rats, monkeys, and humans. Its neural basis seems to lie in a depression of synaptic transmission within the respective sensorimotor pathway (Simons-Weidenmaier et al., 2006; for review, see Glanzman, 2009); however, the underlying molecular mechanism is still not well understood. In mammals, habituation also represents an important sensory filter that reduces the load of sensory information processed by higher brain areas. The appropriate preattentive filtering of inundating sensory information and its integration into other cognitive processes are critical for healthy brain function (Poon and Young, 2006). Habituation can be easily measured as habituation of acoustic startle responses (ASR) in humans and mammalian animal models (Davis, 1984; Braff et al., 1992; Valsamis and Schmid, 2011). Several psychiatric disorders, most prominently schizophrenia and autism, are associated with impairments in ASR habituation (Braff et al., 1992; Ornitz et al., 1993; Perry et al., 
2007). In people with autism spectrum disorder (ASD) disrupted habituation is accompanied with hypersensitivity or hyposensitivity to sensory stimuli, which has a debilitating impact on social interactions and daily functioning (Hirstein et al., 2001; Minshew et al., 2002; Zwaigenbaum et al., 2005; Leekam et al., 2007; Crane et al., 2009; Schoen et al., 2009; Elison et al., 2013; Elsabbagh et al., 2013; Stroganova et al., 2013; for review, see Sinclair et al., 2016).

Knock-out of the gene slo-1, which codes for the pore-forming $\alpha$ subunit of a voltage- and calcium-activated large conductance potassium channel, the BK channel, causes a disruption of habituation in Drosophila (Engel and Wu, 1998). Accordingly, slo-1 knock-out mice display a phenotype reminiscent of ASD, including a lack of startle habituation (Typlt et al., 2013a), along with other cognitive deficits, such as impaired learning (Typlt et al., 2013b), and stereotypic behavior (S.S., unpublished data). Furthermore, a haplo-insufficiency in the gene KCNMA1 (human homolog to slo-1) has been detected in an ASD subject and has subsequently been confirmed in 116 people with autism (Laumonnier et al., 2006).

Based on this evidence, we hypothesized that BK channels play a critical role in synaptic depression underlying ASR habituation. It has been proposed that short-term habituation of startle occurs in the afferent sensory part of startle pathway (Davis and Gendelman, 1977; Davis et al., 1982a, b; Simons-Weidenmaier et al., 2006), specifically through presynaptic depression of auditory afferent synapses on sensorimotor neurons of caudal pontine reticular nucleus (PnC) in the brainstem (Leitner et al., 1980; Lingenhöhl and Friauf, 1992; Weber et al., 2002; Schmid et al., 2003; Simons-Weidenmaier et al., 2006). BK channels are densely expressed in synaptic terminals in cerebral cortex, hippocampus, hypothalamus, brainstem, and spinal cord (Tseng-Crank et al., 1994; Sausbier et al., 2006). BK channels are activated in response to $\mathrm{Ca}^{2+}$ influx and membrane depolarization (Lancaster and Adams, 1986; Lang and Ritchie, 1987). They have been shown to tightly control transmitter release by shortening the duration of presynaptic action potentials (Smith and Ashford, 1998; Hu et al., 2001; Martire et al., 2010; Griguoli et al., 2016) and are therefore well suited to mediate synaptic depression.

We here test the hypothesis that BK channels are functionally expressed in the sensorimotor synapses of the ASR pathway and that they play a critical role in synaptic depression underlying ASR habituation, using a multidisciplinary approach that combines immunohistochemistry, electrophysiology, voltage-sensitive dye imaging (VSDI), and behavioral pharmacology in rats.

\section{Materials and Methods}

Animals. All animal procedures were approved by the University of Western Ontario Animal Care Committee and followed the guidelines of the Canadian Council on Animal Care. Sprague Dawley rats were obtained from Charles River Canada or bred in house. Animals were housed in groups of two or three (except during recovery period after surgery and for breeding) at room temperature $\left(23 \pm 2^{\circ} \mathrm{C}\right)$, on $12 \mathrm{~h}$ light/dark cycle with lights on at 7:00 A.M., and food and water available ad libitum. For behavioral experiments, exclusively adult male rats were used. All other experiments were done with brain slices from male and female animals of the age indicated; sex was not recorded.

Neuroanatomical tracing. Adult rats were anesthetized and a laminectomy was performed to expose the C3-C4 segment. Fluorogold (FG 4\% in saline; Fluorochrome) was injected bilaterally into the spinal cord. Two injections were done per side, 1.6 and $0.8 \mathrm{~mm}$ deep from the dura, $1 \mu \mathrm{l}$ each.

Immunofluorescent staining and analysis. Fourteen days after the FG injections, animals were perfused and brains were harvested, postfixed in the PFA for $1 \mathrm{~h}$, and stored in $15 \%$ sucrose at $4^{\circ} \mathrm{C}$ until completely sunk.
Brainstems were sliced into 5 series of $40 \mu \mathrm{m}$ coronal sections using a freezing microtome (Microm HM $560 \mathrm{M}$ ) and stored at $-20^{\circ} \mathrm{C}$ in cryoprotectant solution (30\% sucrose, $30 \%$ ethylene glycol in $0.1 \mathrm{M} \mathrm{PB}$ with 0.015 sodium azide).

One series of the sections was used to test coexpression of BK channels and vesicular glutamate transporter 1 (VGlut1) on terminals synapsing on retrogradely labeled $\mathrm{PnC}$ giant neurons. Free-floating tissue sections were thoroughly washed in $0.1 \mathrm{M}$ PBS between incubations, and all the incubations were performed at room temperature with gentle agitation. Sections were blocked with $1 \% \mathrm{H}_{2} \mathrm{O}_{2}$ in $0.1 \mathrm{M}$ PBS for 10 min and subsequently incubated in $\mathrm{PBS}^{+}(0.1 \%$ BSA, $0.1 \%$ Triton $\mathrm{X}-100$ in PBS) followed by overnight incubation with rabbit anti-BK (1:1000 in $\mathrm{PBS}^{+}$; Alomone Labs catalog \#APC-021, RRID: AB_2313725), followed by incubation with biotinylated goat anti-rabbit for $1 \mathrm{~h}\left(1: 500\right.$ in $\mathrm{PBS}^{+}$; Vector Laboratories catalog \#BA-1000, RRID: AB_2313606) and by the avidin HRP for $1 \mathrm{~h}$ (ABC-elite, 1:500 in PBS; Vector Laboratories). Next, sections were incubated for $10 \mathrm{~min}$ with biotinylated tyramide (1:250 in PBS with $0.0003 \% \mathrm{H}_{2} \mathrm{O}_{2}$, Tyramid Signal Amplification Biotin Kit, NEL700A001KT, PerkinElmer) and for 30 min with Alexa-633 conjugated streptavidin (1:200 in PBS; Invitrogen catalog \#A32361, RRID: AB_2315383). Sections were then incubated overnight with guinea pig anti-VGlut1 (1:1000 in $\mathrm{PBS}^{+}$; Millipore catalog \#AB5905, RRID: $A B \_2301751$ ) followed by $30 \mathrm{~min}$ in goat anti-guinea pig Alexa-568 in $\mathrm{PBS}^{+}$(Invitrogen catalog\#T20914, RRID: AB_141954). At the end of the staining protocol, sections were washed thoroughly with $0.1 \mathrm{M} \mathrm{PB}$, mounted onto plus-charged glass slides with $0.3 \%$ gelatin in distilled water, and coverslipped with Vectashield mounting medium (Vector Laboratories).

The expression of phosphorylated CREB (pCREB) was tested in 3 animals that received 30 startle stimuli, as well as in 3 rats that were not startled. Tests were performed $60 \mathrm{~min}$ before the animals were perfused. Tissue processing was the same as above, except from the primary antibody: pCREB (Ser 133 mouse monoclonal, 1:1000; Cell Signaling Technology catalog \#9196, RRID: AB_331275), and the secondary antibody, which was biotinylated secondary antibody goat anti-mouse (1:500; Vector Labs catalog \#AI-9200, RRID: AB_2336171).

All images were captured with an SP5 TCS II Confocal Microscope (Leica Microsystems) and LAS AF 2.6 software (Leica Microsystems). The $458 \mathrm{~nm}$ Argon laser was used to excite FG (excitation maximum, 370 $\mathrm{nm})$; FG's wide emission band ( $350-750 \mathrm{~nm})$ due to two emission peaks $(430,610 \mathrm{~nm})$ was filtered to only include signal between 464 and 550 $\mathrm{nm}$. The $633 \mathrm{~nm}$ laser line was used to excite AF 633 (excitation maximum, $631 \mathrm{~nm})$ and the emission filters selected $(670-792 \mathrm{~nm})$ included the emission peak $(647 \mathrm{~nm}$ ) and excluded overlap with FG signals (see Fig. $1 B$ ). Ten percent power was used for each laser and the gain/offset was fixed across all sections. In addition, resolution and signal intensity were increased for all images by setting the line average to 4 and frame accumulation to 2 , respectively. While no alterations were made to actual images, brightness and contrast were adjusted for enhanced viewer observation before inclusion in the results. pCREB images were counted and subjected to statistical analyses. Giant neuron size was determined by calculating the maximum (length) and minimum (width) soma diameters of 20 regular sized FG labeled neurons within the PnC, perpendicular to each other. The means (SDs) of both were calculated, and neurons whose maximum and minimum soma diameters were $3 \mathrm{SD}$ away from the mean were regarded as outliers and characterized as giant neurons. Thus, PnC giant neurons exhibit maximum and minimum diameters that both exceed 36 and $25 \mu \mathrm{m}$, respectively. Based on these criteria, 15 giant neurons across the 3 startle treated animals and 11 across the 3 silence treated animals were selected and manually counted to determine the percentage of $\mathrm{PnC}$ giant neurons in each case that express nuclear pCREB. The expression of pCREB was analyzed by using data from three separate images ( $63 \times$ magnification), for each animal. The number of pCREB-positive cells in each image was counted using Image Pro Premier software (Media Cybernetics) with threshold adjustments made to only include signals between the 40-190 grayscale range.

Brain slice preparation. The $400 \mu \mathrm{m}$ acute brain slices of 11 - to $15-\mathrm{d}$ old pups were cut in ice-cold carbogen-equilibrated preparation solution containing the following (in mM): $2.5 \mathrm{KCl}, 10 \mathrm{MgSO}_{4}, 1.25 \mathrm{NaH}_{2} \mathrm{PO}_{4}, 24$ 
$\mathrm{NaHCO}_{3}, 0.5 \mathrm{CaCl}_{2}-2 \mathrm{H}_{2} \mathrm{O}, 11$ glucose, and 234 sucrose, with a vibratome (Microm, HM650V). Slices were incubated at $32^{\circ} \mathrm{C}$ for $1 \mathrm{~h}$ in ACSF containing the following (in $\mathrm{mM}$ ): $124 \mathrm{NaCl}, 3 \mathrm{KCl}, 3 \mathrm{MgSO}_{4}, 1.25$ $\mathrm{NaH}_{2} \mathrm{PO}_{4}, 26 \mathrm{NaHCO}_{3}, 2.5 \mathrm{CaCl}_{2}-2 \mathrm{H}_{2} \mathrm{O}$, and 10 glucose, continuously bubbled with carbogen $\left(95 \% \mathrm{O}_{2} / 5 \% \mathrm{CO}_{2}\right)$.

Electrophysiology. Electrophysiological experiments were performed as reported previously (Bosch and Schmid, 2006, 2008; Simons-Weidenmaier et al., 2006; Geis and Schmid, 2011). Evoked EPSCs (eEPSCs) were recorded in $\mathrm{PnC}$ neurons in whole-cell voltage-clamp at room temperature while continuously perfused with ACSF (1-2 $\mathrm{ml} / \mathrm{min})$, containing $50 \mu \mathrm{M}$ picrotoxin. Giant PnC neurons were visualized through an upright microscope (Zeiss Axioskop), equipped with an EMCCD camera (Evolve 512, Photometric). Recording electrodes had $4-6 \mathrm{~m} \Omega$ resistance when filled with an intracellular solution containing the following (in $\mathrm{mM}$ ): $140 \mathrm{~K}$-gluconate, $10 \mathrm{KCl}, 1$ $\mathrm{MgCl}_{2}, 10$ HEPES, 0.02 EGTA, $3 \mathrm{Mg}$-ATP, and $0.5 \mathrm{Na}-\mathrm{GTP}, \mathrm{pH}$ adjusted to $7.35,290-300 \mathrm{mosm} / \mathrm{L}$. Signals were sampled at $10 \mathrm{kHz}$, amplified with Axopatch 200B, digitized with Digidata-1550, and analyzed using pClamp10.4 (all Molecular Devices).

VSDI. VSDI experiments were performed as reported previously (Narla et al., 2015). Brainstem slices of adult rats were incubated in the voltage-sensitive dye Di-4-ANEPPS (D-199, Invitrogen) for $35 \mathrm{~min}$ and washed for 8-10 min with ACSF. A platinum electrode (Microprobes) was connected to a S88X dual output square pulse stimulator (Grass Technologies) to stimulate auditory afferents. Optical recordings were acquired at $5 \mathrm{~ms} /$ frame for $2 \mathrm{~s}$ to record background activity, followed by $28 \mathrm{~s}$ with stimulation. Optical signals were recorded by a CMOS camera (Micam Ultima Brain Vision). An excitation filter $\lambda=530 \pm 10 \mathrm{~nm}$ and a long pass emission filter $\lambda>590 \mathrm{~nm}$ were used. Experiments were conducted at room temperature. One or two stripes of 20 pixels each from 4 slices containing PnC region were analyzed using Brain Vision Analyzer (Brain Vision Inc., Japan). At $500 \mathrm{~ms}$ following each $20 \mathrm{~ms}$ burst, stimuli were analyzed for each $5 \mathrm{~ms}$ and averaged for each pixel (25 $\mu \mathrm{m} \times 25 \mu \mathrm{m})$ to detect a change to background activity.

Stereotaxic microinfusion. For local microinfusions into the $\mathrm{PnC}$, rats were stereotaxically implanted bilaterally with 22 gauge stainless steel guide cannulae (C313GA/spc, Plastics One), aiming at the ventrolateral PnC. Stereotaxic microinfusions of $0.5 \mu \mathrm{l}$ of drug or vehicle (1\% DMSO, $0.9 \% \mathrm{NaCl}$ ) were done through inserted injectors (C313LI/spc, Plastics One) before behavioral testing at a rate of $0.1 \mu \mathrm{l} / \mathrm{min}$.

Paxilline, penitrem A, KN-92, KN-93, picrotoxin (all Tocris Bioscience), and BMS-204352 (Sigma-Aldrich) were stocked in 100\% DMSO and stored at $-20^{\circ} \mathrm{C}$. For slice recording, drugs were diluted 1:1000 times in ACSF to a final concentration of $10 \mu \mathrm{M}$ (paxilline, BMS-204352, and penitrem A), $2.5 \mu \mathrm{M}$ (KN-92 and KN-93) or $50 \mu \mathrm{M}$ (picrotoxin). For behavioral experiments, drugs were diluted in saline to the indicated concentration.

Startle testing. Acoustic startle testing was performed as described by Valsamis and Schmid (2011) using commercial startle boxes (Med Associates). Rats were handled for $3 \mathrm{~d}$ before testing to ensure familiarity with the experimenter. Rats were acclimated to the startle chambers (Med Associates) for $5 \mathrm{~min}$ over $3 \mathrm{~d}$. On the last day of acclimation, rats were tested in an input/output (I/O) function consisting of 12 increasing startle pulses (from 65 to $120 \mathrm{~dB}, 5 \mathrm{~dB}$ increments, $20 \mathrm{~ms}$ white noise) to determine the appropriate gain setting for each individual rat that then was maintained throughout the experiments. The testing procedure consisted of the following phases: the acclimation phase, a habituation phase (Block 1), and prepulse inhibition (PPI) measurement (Block 2). During acclimation, rats were exposed to the chambers and white background noise (65 dB) for 5 min. During Block 1, 50 pulse alone trials (110 dB white noise, $20 \mathrm{~ms}$ duration) were delivered at $15 \mathrm{~s}$ intertrial intervals. Block 2 consisted of five different trials presented 10 times each in a pseudo-randomized order at $15 \mathrm{~s}$ intertrial interval: pulse-alone trials, and four different prepulse-pulse trial types with either $75 \mathrm{~dB}$ or $85 \mathrm{~dB}$ prepulses ( $4 \mathrm{~ms}$ white noise), preceding the startle pulse by either 30 or $100 \mathrm{~ms}$ (interstimulus interval). For habituation analysis, all startle responses were normalized to the average of the first two responses and then averaged to plot the habituation curve. PPI was calculated for each animal and each trial type as PPI $(\%)=(1-$ average startle amplitude to pulse with prepulse/average startle amplitude to pulse only) $\times 100$. To verify the position of cannula, $0.2 \mu$ l of thionine dye was injected into the brains of deeply anesthetized rats before death. Animals were then transcardially perfused, brains were removed, postfixed in $4 \%$ PFA, stored in $30 \%$ sucrose, and cut into $50-\mu \mathrm{m}$-thick coronal sections. After mounting on slides and air dried, the slices were stained with thionine.

Statistical analysis. Data acquisition, analyses, and presentation were performed using a combination of pClamp10.4 (Molecular Devices), SPSS version 14 (IBM), and the Sigma Plot 11 (Jandel Scientific). Data are mean \pm SEM unless stated otherwise. $p$ values of $<0.05$ were considered statistically significant. Paired or independent samples $t$ tests, and repeated-measures two-way ANOVA were used for detecting statistical differences where appropriate and as stated with the respective results.

\section{Results}

\section{BK channels are localized predominantly on glutamatergic} terminals synapsing onto giant neurons in the PnC

The primary acoustic startle pathway comprises three serially connected central structures: spiral ganglion cells that innervate the cochlear hair cells and synapse on cochlear root neurons that in turn project to the reticular formation and synapse on giant neurons in the PnC. The PnC giant neurons serve as sensorimotor interface and innervate cervical and spinal motor neurons that rapidly activate muscle contractions (Koch, 1999). It has been shown that the primary and secondary auditory afferents use glutamate as neurotransmitter (Hackney et al., 1996; Zhou et al., 2007; Gómez-Nieto et al., 2014). To determine whether BK channels are colocalized with glutamatergic synaptic terminals on startle mediating PnC neurons, we first combined retrograde tracing of startle neurons from the spinal cord with immunostaining for pCREB to confirm that giant neurons in the PnC were activated by startle. We subsequently combined NeuN staining with labeling for BK channels and for VGluT1, to show the expression of BK channels on glutamatergic synapses onto these startle-mediating giant neurons in the PnC. Our results showed that FG tracer injection into C3/C4 segments of the cervical spinal cord of rats predominantly labeled giant neurons within the PnC with average soma diameters of $48.7 \pm 0.88 \mu \mathrm{m}$ and $31.7 \pm 0.70 \mu \mathrm{m}$, length and width, respectively $(n=73$; Fig. $1 A)$. More than half $(53 \pm 0.13 \%)$ of retrogradely labeled giant PnC neurons with a soma length $>36 \mu \mathrm{m}$ and a width $>25 \mu \mathrm{m}$ expressed pCREB in animals killed after eliciting startle responses ( $n=15$ cells from 3 animals), whereas none of the giant neurons expressed pCREB in animals that were not startled $(n=11$ cells from 3 animals; Fig. $1 B$ ), confirming that giant neurons in the $\mathrm{PnC}$ are selectively activated during startle. Subsequently, PnC giant neurons were stained using a NeuN antibody, and glutamatergic terminals contacting PnC giant neurons, a potential site of plasticity underlying habituation (see Introduction), were labeled using VGluT1 and BK channel antibodies. BK channels were shown to be colocalized on $86 \pm 3.7 \%$ of glutamatergic terminals in the PnC (Fig. 1C). The double-labeled terminals contacted PnC giant neurons mainly at the soma and proximal dendrites, which is in accordance with the requirement of the very fast and efficient signal transmission during startle.

In summary, the immunohistochemical results confirm an expression of BK channels at glutamatergic terminals synapsing on startle mediating giant neurons in the PnC.

\section{BK channels regulate synaptic transmission in the $\mathrm{PnC}$}

We next examined the functional role of BK channels in these glutamatergic terminals using whole-cell voltage-clamp recordings. Presynaptic glutamatergic fibers were stimulated ventrolateral to the lateral superior olive, as shown in Figure $2 \mathrm{~A}$ (see also Weber et al., 2002; Simons-Weidenmaier et al., 2006). eEPSCs 
A1

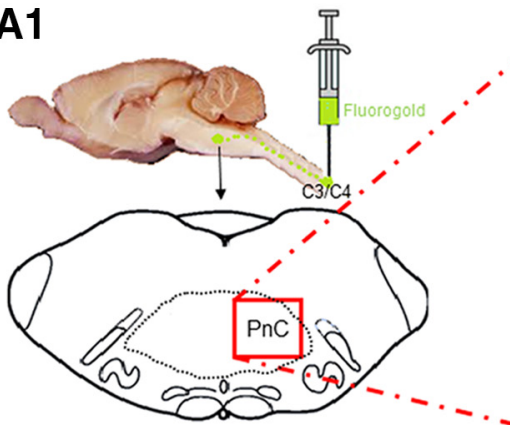

B
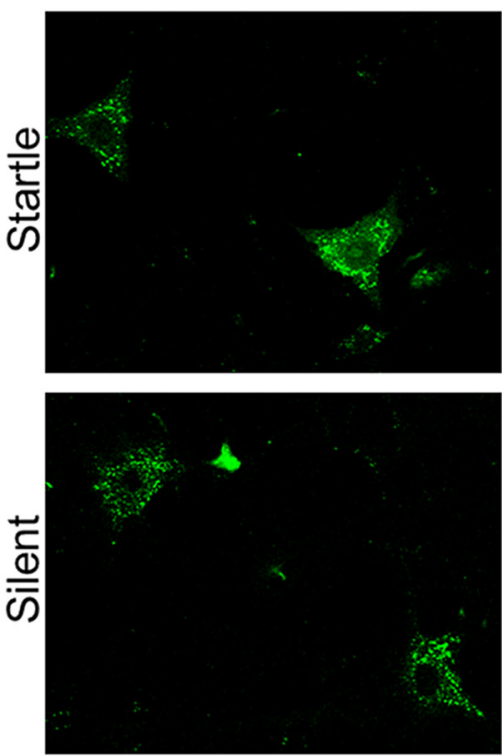

c

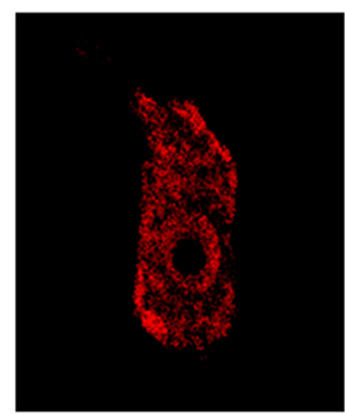

NeuN
A2
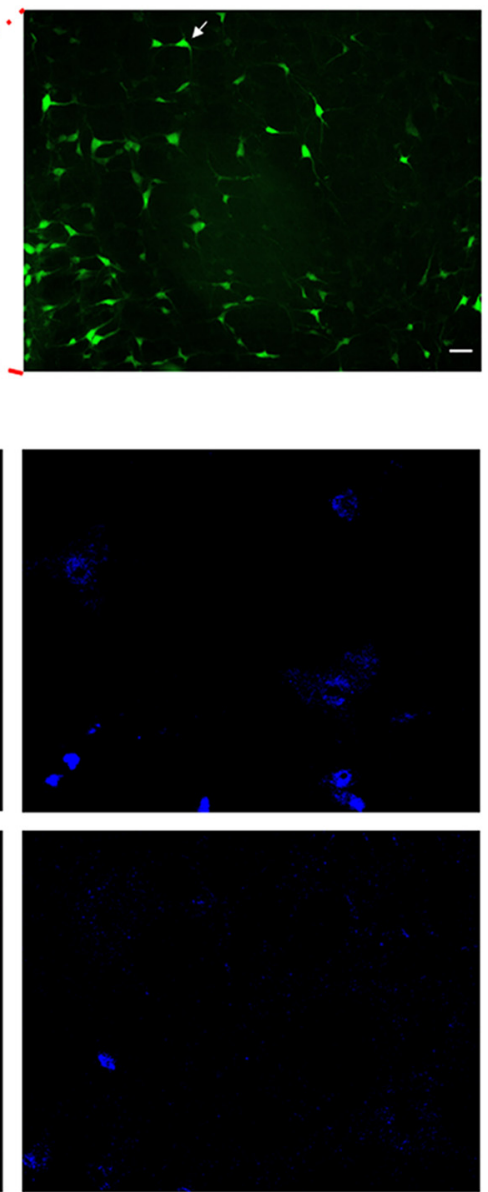

pCREB

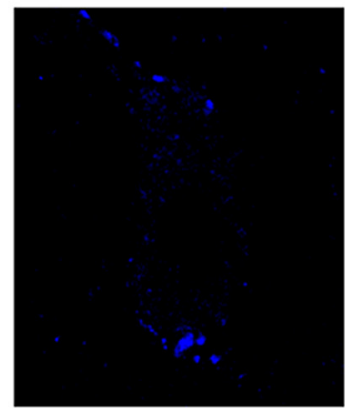

BK Channel
A3
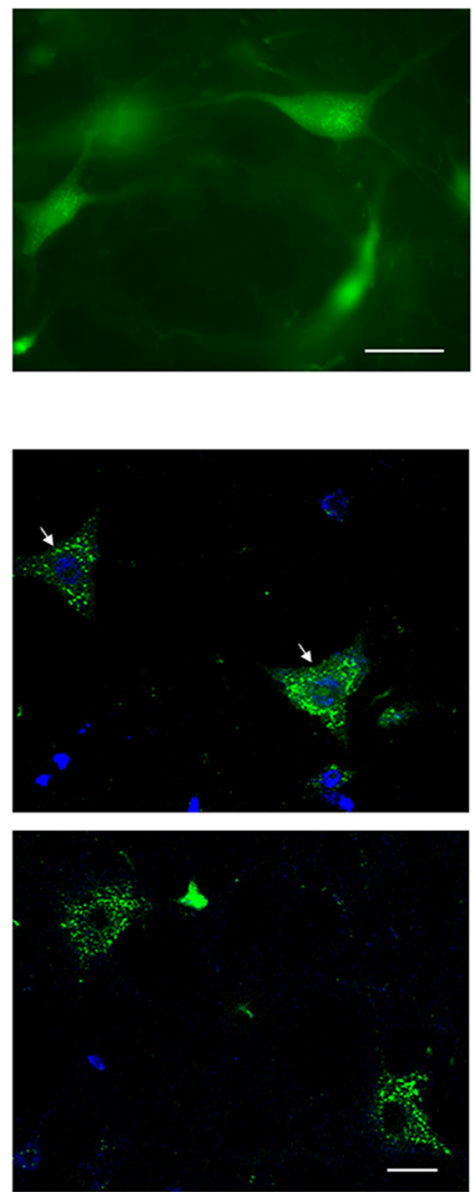

Merged

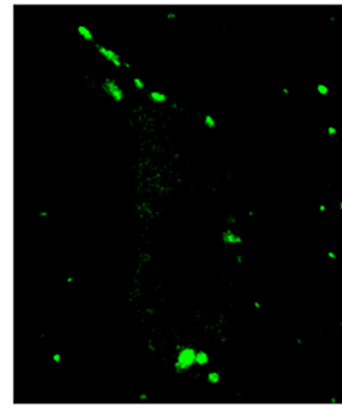

VGlut1

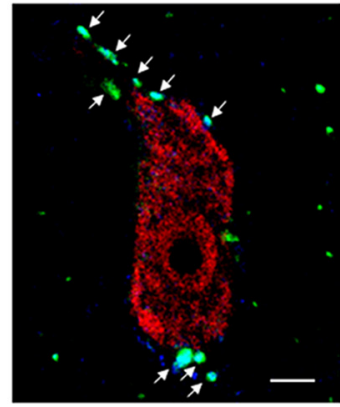

Merged

Figure 1. BK channels are colocalized with VGluT1 on glutamatergic sensorimotor synapses on PnC giant neurons. $\mathbf{A 1}$, FG tracers were injected into the spinal cord at the $33 / C 4$ intervertebral level. A2, On the level of the brainstem, retrogradely labeled neurons ( green) are abundant in the PnC region and have a large soma diameter. Scale bar, $50 \mu \mathrm{m}$. $\mathbf{A}$, A higher magnification of retrogradely labeled giant PnC neurons with FG particles. Scale bar, $50 \mu \mathrm{m}$. B, Representative images of labeled cells in the PnC of animals that were startled 60 min before death, and animals that were held in silence. FG-labeled PnC giant neurons (green) colocalize with pCREB (blue) in animals that were startled (arrows), but PnC giant neurons showed no pCREB labeling in animals that were not startled. Scale bar, $25 \mu \mathrm{m}$. C, Representative images of PnC giant neurons labeled with NeuN (red) and expression of VGluT1 (green) and BK channels (blue) in glutamatergic terminals synapsing onto their cell bodies. Arrows indicate colocalization of vGluT1 and BK channels. Scale bar, $10 \mu \mathrm{m}$. All images are single planes in a $z$-stack taken of $\sim 30-50$ steps; thickness of each section is $40 \mu \mathrm{m}$.

were recorded from visually identified PnC giant neurons. To assess the functional role of BK channels, we perfused the selective blocker paxilline with the bath solution and delivered standard paired pulse stimulation with an interstimulus interval of 50 ms. eEPSC amplitudes trended to increase during the application of $10 \mu \mathrm{M}$ paxilline $(161 \pm 23.4 \mathrm{pA}$ in control vs $231 \pm 31.5 \mathrm{pA}$ in paxilline; $p=0.061 ; n=17$ cells; Fig. $2 B$ ), while the paired pulse ratio (PPR: eEPSC2/eEPSC1) was significantly decreased by pax- illine $(1.42 \pm 0.07$ in control vs $1.01 \pm 0.05$ in paxilline; $p<$ $0.001, n=17$; Fig. $2 C, D$ ). This suggests that $\mathrm{BK}$ channels are activated when a single action potential reaches the synaptic terminal. The activation of BK channels reduces the duration of depolarization, hence calcium influx and transmitter release. Our results suggest that $\mathrm{BK}$ channels modestly reduce neurotransmitter release during baseline synaptic transmission of single action potentials, which leads to a slight increase of the PPR due to a 
A

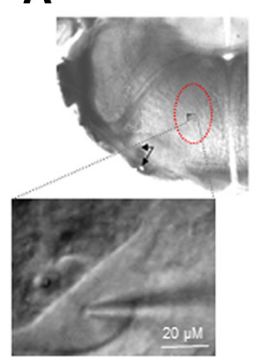

B

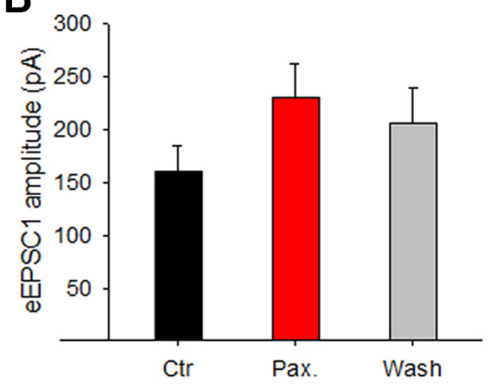

C

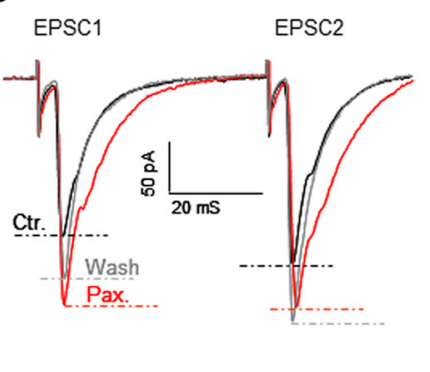

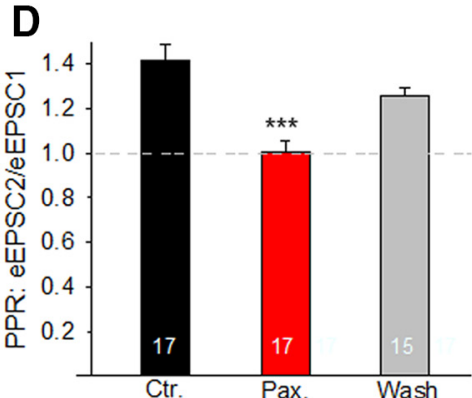

E

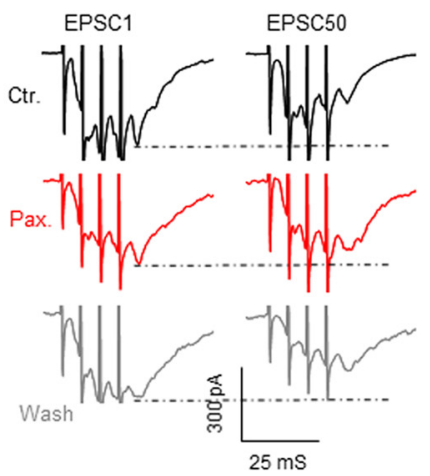

F

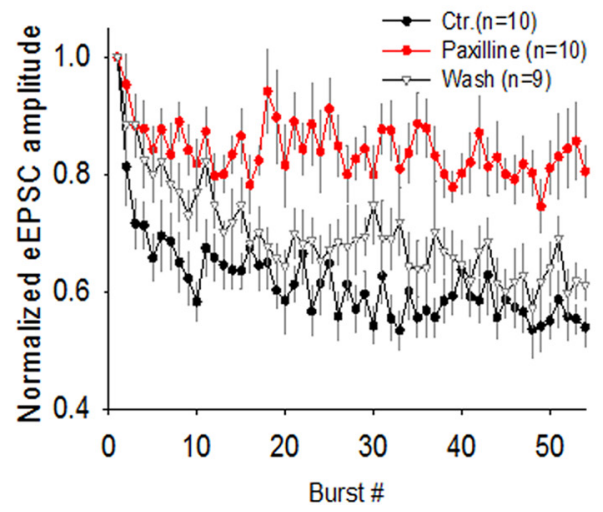

G

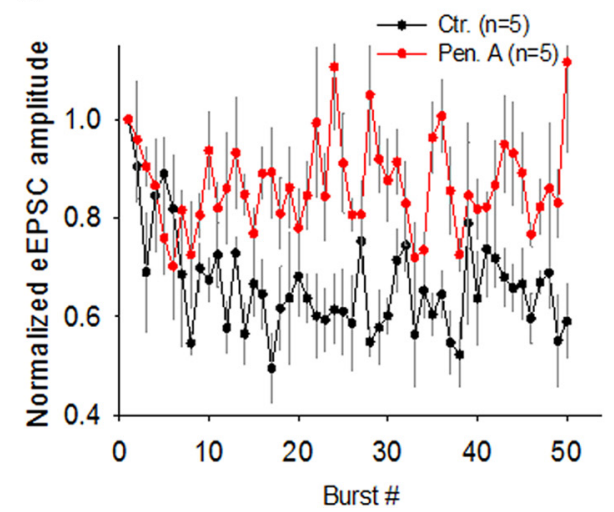

Figure 2. Pharmacological inhibition of BK channels increases release probability and reduces synaptic depression at sensorimotor synapse in the PnC. $A$, A differential interference contrast image from recording chamber showing regions stimulated (arrows) and recorded (red circle) with closer look of the patched neuron. $\boldsymbol{B}$, Mean EPSC1 amplitudes evoked by auditory afferent fiber stimulation trended to be higher but were not significantly increased by paxilline ( $p=0.061)$. C, Representative traces showing the amplitude of EPSCs. D, PPR (EPSC2/EPSC1 amplitude) under different experimental conditions. The PPR was significantly reduced by paxilline ( $\left.{ }^{* * *} p<0.001\right)$. $A-D$, Control (Ctr., $\left.n=17\right)$, paxilline 10 $\mu$ m (Pax., $\left.n=17\right)$, and washout (Wash, $\left.n=15\right)$. Data are mean \pm SEM. $\boldsymbol{E}$, Representative traces showing EPSCs evoked by first and 50th high-frequency $(200 \mathrm{~Hz})$ burst stimuli, delivered at $1 \mathrm{~Hz}$. $\boldsymbol{F}$, Synaptic depression was significantly reduced by paxilline $(p<0.001)$. G, Penitrem A also significantly reduced synaptic depression ( $p=0.024)$. $\boldsymbol{F}, \mathbf{G}$, eEPSC amplitudes were normalized to the amplitude of first EPSC for each cell and then averaged across cells, presented as mean \pm SEM.

better preserved readily releasable neurotransmitter vesicle pool after the first pulse.

We have previously proposed that short-term habituation of acoustic startle is mediated by activity-dependent synaptic depression of these glutamatergic synapses in the $\mathrm{PnC}$, induced by "bursts" (i.e., short trains of four or more action potentials at $100-150 \mathrm{~Hz}$ ), which mimics their activity pattern during startle in vivo (Weber et al., 2002; Simons-Weidenmaier et al., 2006). To test whether BK channels play a functional role in the activitydependent depression of these synapses, we induced synaptic depression under different experimental conditions as described previously (Weber et al., 2002; Simons-Weidenmaier et al., 2006; Schmid et al., 2010). While we observed synaptic depression of eEPSCs to an average of $56 \%$ of initial eEPSC amplitudes under control conditions $(p<0.001)$, synaptic depression was attenuated in the presence of paxilline to only $81 \%$ of initial amplitudes ( $n=10$ cells). A two-way repeated-measures ANOVA revealed a significant effect of trials $\left(F_{(2,99)}=6.469 ; p<0.001\right)$, confirming significant synaptic depression; a significant effect of drug $\left(F_{(2,99)}=22.599 ; p<0.001\right)$, and an interaction of drug and trial: $\left(F_{(2,99)}=1.198 ; p=0.039\right)$, indicating that synaptic depression is altered by paxilline (Fig. $2 E, F$ ). After a recovery and washout period of at least 10-15 min, synaptic depression could be induced to almost the same level as under control conditions, to an average of $62 \%$ of initial amplitudes ( $n=9$ cells; Fig. $2 E, F)$. We subsequently verified these results using another potent general $B K$ channel blocker, penitrem $A$. ANOVA revealed again a significant effect of trial $\left(F_{(2,49)}=1.857 ; p=0.002\right)$, of drug $\left(F_{(2,49)}=\right.$
$12.584 ; p=0.024)$ and a significant interaction of drug and trial $\left(F_{(2,49)}=1.97 ; n=5 ; p<0.001\right.$; Fig. $2 G ; n=5$ cells $)$. These results suggest that synaptic depression within the primary startle pathway induced by repeated high-frequency stimulation of afferent fibers (thereby mimicking their activity during presentation of an acoustic startle stimulus) is dependent on the activation of BK channels.

\section{Persistent synaptic depression requires BK channel phosphorylation}

Generally, this depression of EPSCs lasted for several minutes before amplitudes recovered to the baseline (Weber et al., 2002). Transient BK channel activation alone therefore cannot account for the lasting effect in the range of minutes, as observed as synaptic depression in the $\mathrm{PnC}$, or behaviorally as short-term habituation of startle. The lasting decrease in synaptic efficacy indicates a possible role of BK channel phosphorylation, potentially by presynaptic $\mathrm{Ca}^{2+} /$ calmodulin-dependent protein kinase II (CaMKII). CaMKII is activated by $\mathrm{Ca}^{2+}$ influx and autophosphorylates upon massive accumulation of $\mathrm{Ca}^{2+}$ (e.g., during high frequency burst stimulation), so that its activity persists even after termination of $\mathrm{Ca}^{2+}$ influx (Liu et al., 2007). Indeed, we have previously shown that synaptic depression in the $\mathrm{PnC}$ is dependent on high-frequency trains of at least four action potentials (Simons-Weidenmaier et al., 2006). To determine whether phosphorylation of BK channels by CaMKII accounts for the lasting decrease in synaptic efficacy, we incubated brain slices with the potent and selective CaMKII inhibitor KN-93 (Rokhlin 
A

EPSC1

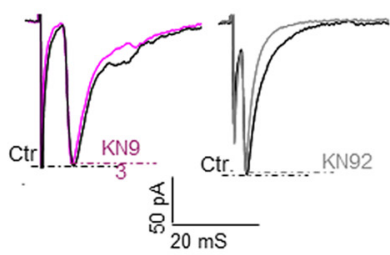

B

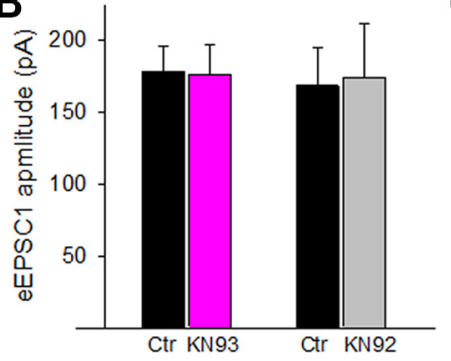

C

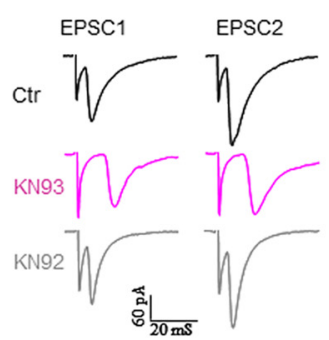

D

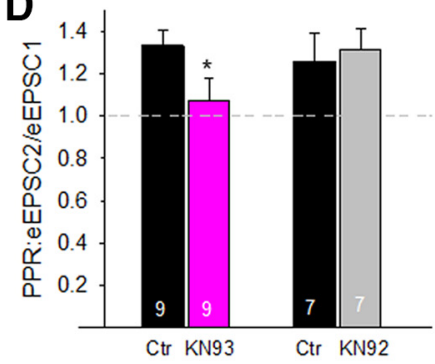

E F

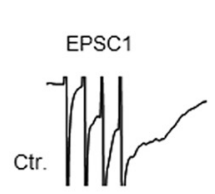

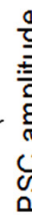

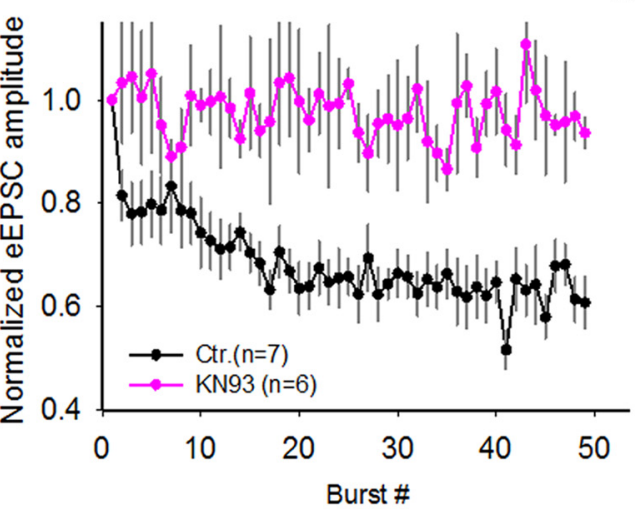

G

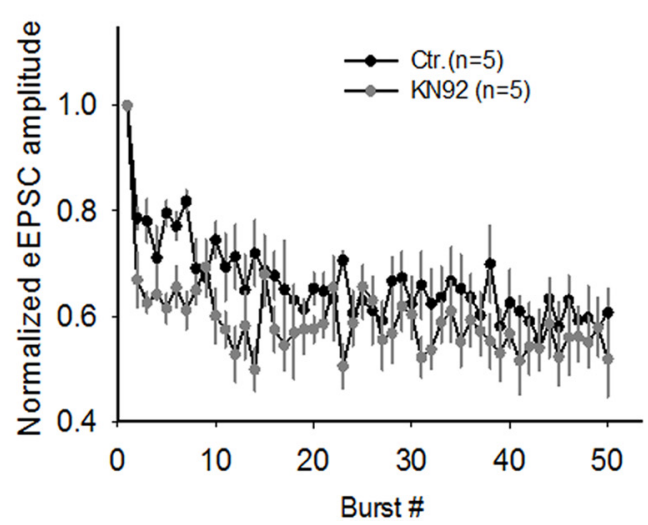

Figure 3. CaMKII phosphorylation inhibitor KN-93 reduces synaptic depression. Sample traces $(\boldsymbol{A})$ and average amplitude $(\boldsymbol{B})$ of EPSC1 under control condition (Ctr) and after incubation with KN-93 (2.5 $\mu \mathrm{M}, 40 \mathrm{~min}$ ) or its ineffective derivate KN-92 (2.5 $\mu \mathrm{M}, 40 \mathrm{~min}$ ). EPSC1 amplitudes were not affected by KN-93 ( $p=0.901)$ or KN-92 ( $p=0.909)$. Sample traces ( $C$ ) and paired pulse ratios (D) after incubation with the CaMKII inhibitor KN-93 or KN-92. The PPR is significantly reduced by KN-93 ( $\left.{ }^{*} p=0.018\right)$, but not by KN-92 ( $\left.p=0.462\right)$. C, $\boldsymbol{D}, n=9$ cells for KN-93, and $n=7$ cells for KN-92. Data are mean \pm SEM. $\boldsymbol{E}$, EPSC1 and EPSC50 sample traces evoked by burst stimuli. $\boldsymbol{F}$, Synaptic depression was blocked after incubation with KN-93 ( $p=0.02$ ). $\mathbf{G}$, Synaptic depression was not changed by incubation with KN-92 $(p=0.42)$. Data are mean \pm SEM.

et al., 2010), or with its inactive derivate KN-92. EPSC1 amplitudes evoked by single action potentials were not significantly affected after a $40 \mathrm{~min}$ incubation in $2.5 \mu \mathrm{M} \mathrm{KN}-93$ (eEPSC1, $p=$ $0.901)$; however, PPR was slightly decreased $(p=0.018)$ as in the presence of paxilline (see above), indicating that some BK channels might be phosphorylated even in baseline synaptic transmission. The ineffective derivate $\mathrm{KN}-92$ had no effect on eEPSC1 $(p=0.909)$ or PPR $(p=0.738$; paired $t$ test, Fig. $3 A-D)$. Synaptic depression following repeated burst stimulation was greatly reduced in KN-93 treated PnC neurons ( $n=7$ cells). A two-way repeated-measures ANOVA confirmed a significant effect of drug: $\left(F_{(1,49)}=11.337 ; p=0.02\right)$ and an interaction of drug and trial $\left(F_{(1,49)}=1.440 ; p=0.039\right.$; Fig. $\left.3 E, F\right)$, confirming that inhibition of CaMKII phosphorylation impeded synaptic depression. There was no effect on synaptic depression in neurons incubated with KN-92 $\left(n=5\right.$ cells; drug: $F_{(1,49)}=0.808 ; p=$ 0.420 ; interaction drug and trial: $F_{(1,49)}=0.997 ; p=0.488$; twoway repeated-measures ANOVA; Fig. $3 G$ ). These results support the idea that phosphorylation of BK channels by CaMKII, rather than just their activation, is required to induce lasting synaptic depression in the PnC, presumably underlying short-term habituation of ASR.

\section{Positive modulation of BK channels}

Because BK channel antagonists inhibit synaptic depression, we wanted to test whether positive modulation of BK channels could enhance synaptic depression. We used the potent BK channel opener BMS-204352 and ran the standard paired pulse protocol (see above). BMS-204352 had no significant effect on eEPSC1 amplitudes ( $148 \pm 13.3 \mathrm{pA}$ in control vs $149 \pm 31.5 \mathrm{pA}$ in BMS$204352 ; p=0.937$; paired $t$ test; Fig. $4 A)$ or on PPR $(1.42 \pm 0.066$ in control vs $1.38 \pm 0.07$ in BMS-204352; $p=0.413$; paired $t$ test; Fig. $4 B, C)$. Synaptic depression induced by burst stimulation with or without the presence of the BK channel opener, however, revealed a significant effect of BMS-204352 ( $n=9$ cells, trial: $F_{(1,49)}=5.484 ; p=0.001$; drug: $F_{(1,49)}=18.027 ; p=0.003$; interaction drug and trial: $F_{(1,49)}=1.647 ; p=0.006$; two-way repeated-measures ANOVA; Fig. $4 D, E)$. Surprisingly, the amount of synaptic depression was reduced in the presence of BMS-204352; however, this refers to the data normalized to the amplitude in response to the first burst stimulation under each condition. Further analysis of the first burst evoked EPSC amplitudes revealed that, under BMS-204352 conditions, amplitudes were $\sim 20 \%$ lower than under control conditions, indicating that synaptic depression already affected eEPSC amplitudes evoked by the first burst in the BMS-204352 condition. We therefore normalized the BMS-204352 data to the first amplitude under control condition of each cell and found that there is no effect of BMS-204352 on the level of synaptic depression $\left(F_{(1,49)}=1.279\right.$, $p=0.291$; two-way repeated-measures ANOVA; Fig. $4 F)$.

In summary, our results suggest that bath perfusion the BK channel opener BMS-204352 greatly facilitates synaptic depression, leading to faster (but not stronger) synaptic depression that sets in during the first burst stimulation already.

\section{BK-induced synaptic depression suppresses the population activity in the PnC}

Because whole-cell patch-clamp recordings allow only to look at a single-cell level and in juvenile rats, we next combined presynaptic burst stimulation with VSDI to visualize the functional role of BK channels in dynamics of general PnC activity in the adult. Stimulation of glutamatergic fibers evoked overall excitatory re- 
A

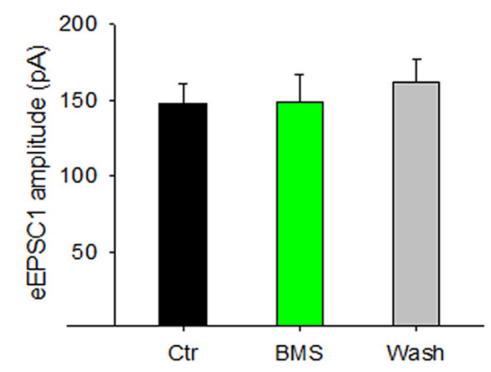

D

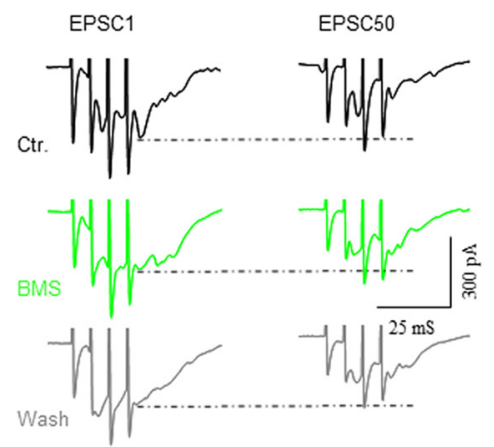

B

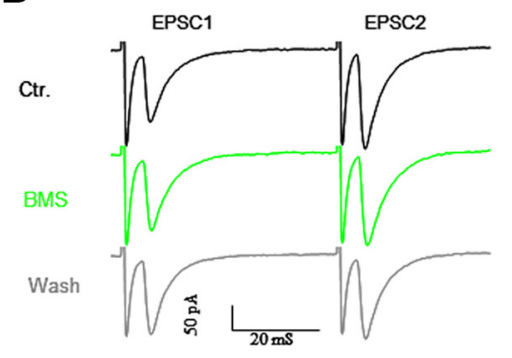

$\mathbf{E}$

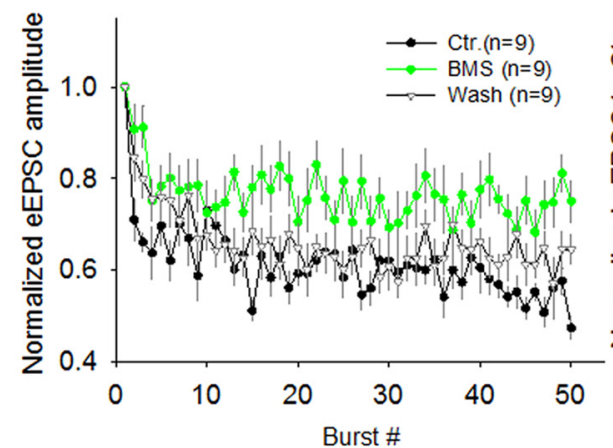

C

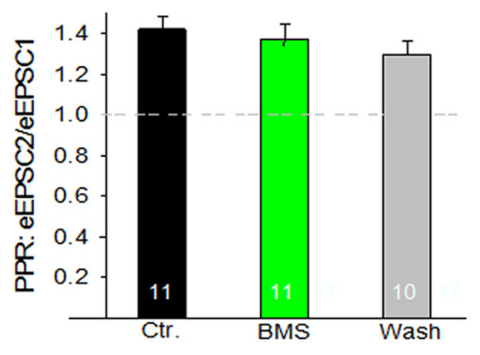

$\mathbf{F}$

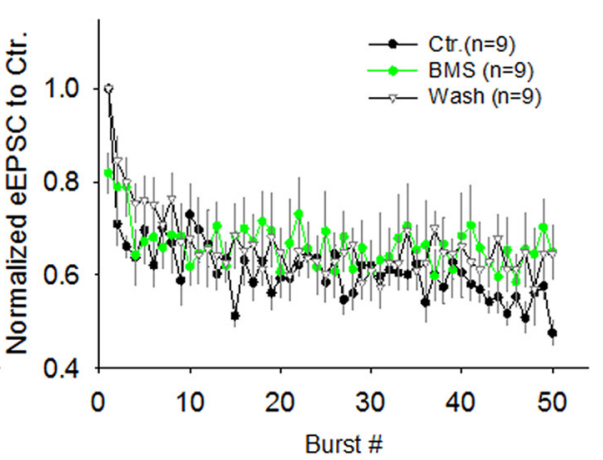

Figure 4. Effect of the BK channel opener BMS-204352 on synaptic transmission and synaptic depression. $A$, BMS-204352 (10 $\mu \mathrm{M})$ had no effect on amplitude of evoked EPSCs ( $p=0.937)$. $B$, Sample traces of evoked EPSCs by a standard paired pulse stimulation protocol. C, BMS-204352 had also no effect on the PPR $(p=0.413)$. D, Sample traces showing EPSC1 and EPSC50 evoked by burst stimulation under different drug conditions. $E$, Bath application of BMS-204352 seemed to attenuate synaptic depression when EPSC amplitudes were normalized to the first amplitude of each condition $(p=0.001)$. $\boldsymbol{F}$, Because the first EPSC amplitude during BMS-204352 application tended to be $20 \%$ lower than under control conditions, BMS-204352 amplitudes were normalized to EPSC1 of the control condition for each cell. This revealed that BMS-204352 did not change synaptic depression $(p=0.291)$. Data are mean \pm SEM.

sponses in a large number of scattered pixels in the PnC, confirming that presynaptic stimulation activates a large population of neurons in the PnC (Fig. $5 A, B$ ). Consistent with our electrophysiological findings, we observed an attenuation of evoked neuronal activity upon repeated burst stimulation under control conditions (fluorescent change: $0.69 \pm 0.15$ after train 1 vs $0.17 \pm$ 0.051 after train $22 ; n=4$ slices, $p=0.031$, paired $t$ test). When the BK channel blocker penitrem A was applied, we saw not only less attenuation upon repeated stimulation, but a significant increase in evoked PnC neural activity (fluorescent change: $0.47 \pm$ 0.032 after train 1 vs $0.96 \pm 0.12$ after train $22 ; p=0.008$; Fig. $5 C$ ). Similarly, the number of hyperpolarized pixel units in the $\mathrm{PnC}$ was greatly reduced after pharmacological inhibition of BK channels (control: $35 \% \pm 2.9$ after train 1 vs $43.7 \pm 6.25 \%$ after train $22 ; p=0.243$; penitrem A: $35 \% \pm 6.12$ after train 1 vs $2.5 \pm 2.5 \%$ after train 22; Fig. 5D). While mainly confirming the electrophysiological results, this indicates that BK channel blocker may also affect other neuronal cell populations within the PnC that become more excitable upon BK channel blockage.

In summary, these results show that stimulation of the auditory afferent pathway yield widespread excitation in the PnC. In accordance with our electrophysiological results, this excitation attenuates upon repeated burst stimulation under control conditions, whereas in presence of the $\mathrm{BK}$ channel blocker, $\mathrm{PnC}$ excitation shows a cumulative increase upon repeated burst stimulation.

\section{BK channel modulation of startle habituation}

Based on our findings above, we asked whether modulation of BK channels in the PnC in vivo can influence ASR habituation. Because BK channels are abundantly expressed in the periphery and in the CNS, we chose to locally infuse respective drugs into the
PnC, so that we would not get any confounding side effects. The blockers penitrem A and paxilline, the opener BMS-204352, or the vehicle alone were bilaterally infused into the PnC before behavioral testing for short-term habituation, using stereotaxically implanted guide cannulas. ANOVA revealed a significant effect of trials for all conditions, confirming that habituation took place. There were no significant effects of drug in the group locally infused with paxilline $\left(F_{(1,29)}=0.567 ; p=0.473 ; n=9\right)$ or the group infused with penitrem $\mathrm{A}\left(F_{(1,29)}=1.664 ; p=0.226\right.$; $n=11$; two-way repeated-measures ANOVA; Fig. 6A1). In contrast, microinfusion of BMS-204352 led to a significant enhancement of short-term habituation of the startle response compared with vehicle-injected control. A two-way repeated-measures ANOVA revealed a significant effect of $\operatorname{drug}\left(F_{(1,29)}=7.437 ; p=\right.$ $0.012 ; n=24$; Fig. $6 B 1)$. Notably, the habituation score, an average of ASR amplitudes of trials 20-30, normalized to the average of first ASR amplitude of the test session, was significantly increased in $0.1 \mathrm{~mm}$ BMS-204352-injected rats $(0.248 \pm 0.037 ; p=$ 0.007; Fig. 6B3) but was not changed in paxilline-injected $(0.392 \pm 0.052 ; p=0.473)$, or penitrem A-injected rats $(0.424 \pm$ $0.097 ; p=0.923$; Fig. 6 A3) compared with that in vehicle-injected rats $(0.437 \pm 0.054$, paired $t$ test). Placements of injection cannula were confirmed postmortem and only animals with cannula ending within the boundary of the PnC on both sides were included in the analysis (Fig. 6C).

It is important to note that we did not observe any significant drug effect on baseline startle amplitudes with any of the drugs: paxilline ( $p=0.426)$; penitrem A ( $p=0.912$; Fig. $6 A 2)$; or BMS204352 ( $p=0.877$; Fig. $6 B 2$ ).

Also, in contrast to the findings in BK channel knock-out mice that showed a mild impairment in prepulse inhibition of startle (a 
A

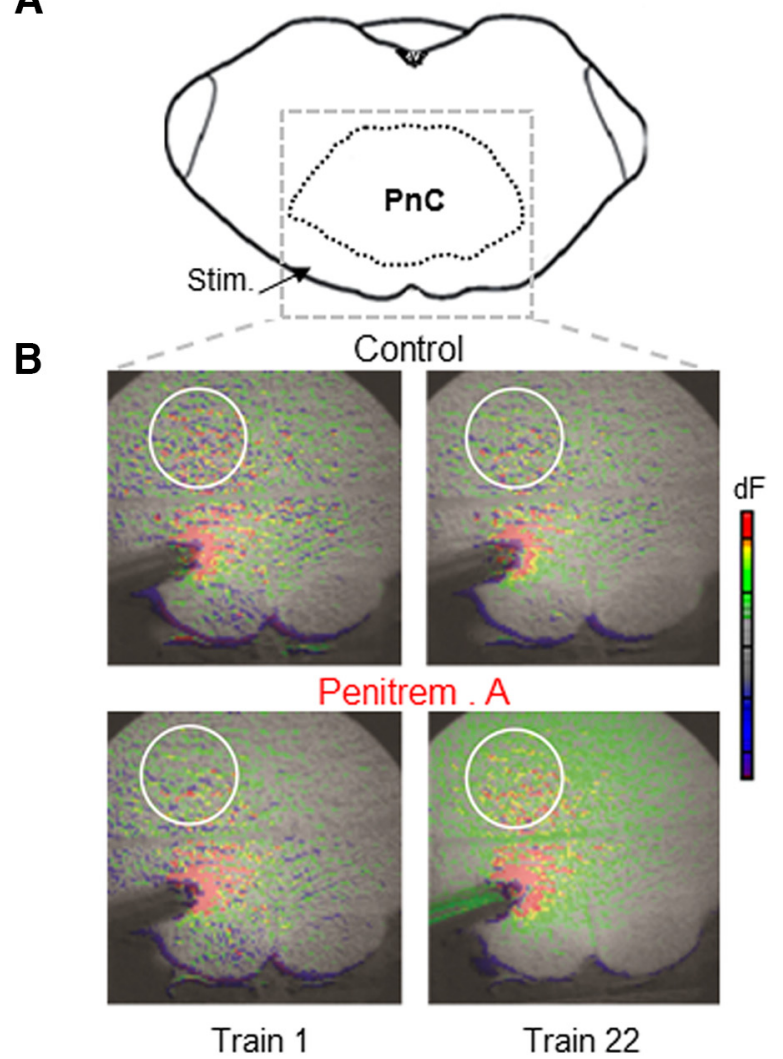

C
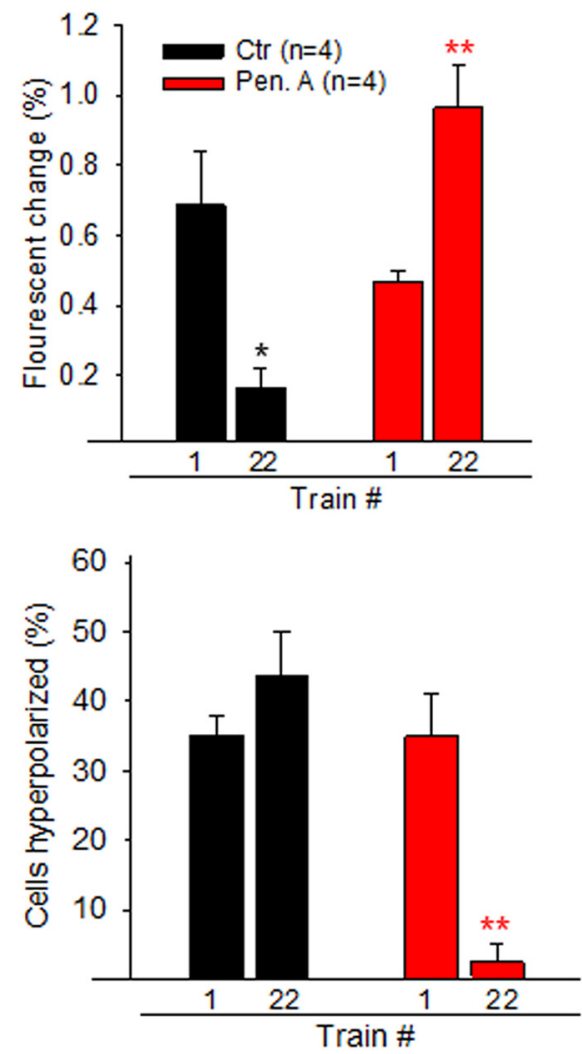

Figure 5. VSDI validates the spatiotemporal role of BK channels in startle mediating circuit. $\boldsymbol{A}$, Schematic of the slice containing the PnC and the portion that was imaged in $\boldsymbol{B}$ under differential experimental conditions. $\boldsymbol{B}$, Representative fluorescent images following the delivery of high-frequency burst stimulation as used in electrophysiological conditions above under control conditions and in presence of penitrem $A(1 \mu \mathrm{m}, 10 \mathrm{~min}$ ): red, yellow, and green represent neuronal excitation; blue and magenta represent inhibition. $\boldsymbol{C}$, Bar graph showing the overall fluorescent change in a $500 \mathrm{~ms}$ window after burst stimulation as mean \pm SEM in stripes of 20 pixels from the PnC region lined out by a white circle. While there is a decrease in excitation under control conditions after 22 burst stimulations ( ${ }^{*} p=0.031$ ), there is a significant increase in excitation when BK channels were blocked by penitrem $\mathrm{A}\left({ }^{* *} p=0.008\right)$. Each pixel represents activity in $25 \mu \mathrm{m} \times 25 \mu \mathrm{m}$ imaged field. $\boldsymbol{D}$, The number of pixels hyperpolarized stayed the same under control conditions $(p=0.243)$, whereas the number significantly decreased in presence of penitrem $A(* * p=0.003)$. $n=4$ slices per treatment. Data are mean \pm SEM.

measure of sensorimotor gating) (Typlt et al., 2013b), there was also no significant drug effect on prepulse inhibition of startle by 75 and $85 \mathrm{~dB}$ prepulses, respectively, at $30 \mathrm{~ms}$ interstimulus interval (paxilline: $p=0.108$ and $p=0.734$; penitrem A: $p=0.884$ and $p=0.168$; and BMS-204352: $p=0.869$ and $p=0.833$ ) or 100 ms interstimulus interval (paxilline: $p=0.432$ and $p=0.149$; penitrem A: $p=0.695$ and $p=0.260$ and BMS-204352: $p=$ 0.533 and $p=0.855$, paired $t$ tests; data not shown), suggesting that $\mathrm{BK}$ channels in the $\mathrm{PnC}$ are important for short-term habituation, but do not regulate baseline startle responses or prepulse inhibition.

In summary, our findings indicate that BK channel activation and subsequent phosphorylation upon strong synaptic stimulation are critical for inducing synaptic depression within startle pathway, underlying short-term habituation of the ASR. Our results also indicate that synaptic depression in the PnC might not be the only site of plasticity for short-term habituation of startle, and that habituation can be enhanced by targeting BK channels.

\section{Discussion}

\section{Neural mechanisms underlying short-term habituation} of startle

Based on the data presented here. we propose that ASR habituation is at least to some extent caused by the phosphorylation of $\mathrm{BK}$ channels in presynaptic glutamatergic terminals in the PnC. $\mathrm{BK}$ channels are generally activated by increases in intracellular calcium and depolarization during presynaptic action potentials. BK channel activation hyperpolarizes the membrane, shortening the action potential, and thereby tightly limiting neurotransmitter release (Robitaille et al., 1993, 2004; Womack and Khodakhah, 2003; Sausbier et al., 2004; Sailer et al., 2006). BK channels seem to play a minor role in regulating transmitter release in the sensorimotor synapses in the $\mathrm{PnC}$ in response to a single action potential because we only saw subtle changes, mostly in PPR, following BK channel inhibition. Upon stimulation with a short train of action potentials (a stimulation paradigm that reflects the activity of auditory neurons upon acoustic stimulation in vivo), presynaptic calcium accumulates and BK channels seem to become more active, resulting in reduced transmitter release and synaptic depression. The requirement of strong synaptic activation (Simons-Weidenmaier et al., 2006), along with the fact that synaptic depression lasts for several minutes (Weber et al., 2002; Schmid et al., 2003), led us to hypothesize that BK channels become not only activated, but also phosphorylated, rendering them more calcium-sensitive. This leads to a faster repolarization of the synapse and thereby reduced synaptic efficacy (Wang, 2008). It has been shown that a broad spectrum of kinases, including CaMKII, regulate BK channel activity (Tian et al., 2003; Liu et al., 2007; Wang, 2008; van Welie and du Lac, 2011). CaMKII phosphorylation of BK channels has been shown to be critical for synaptic depression in the neuromuscular junction in 

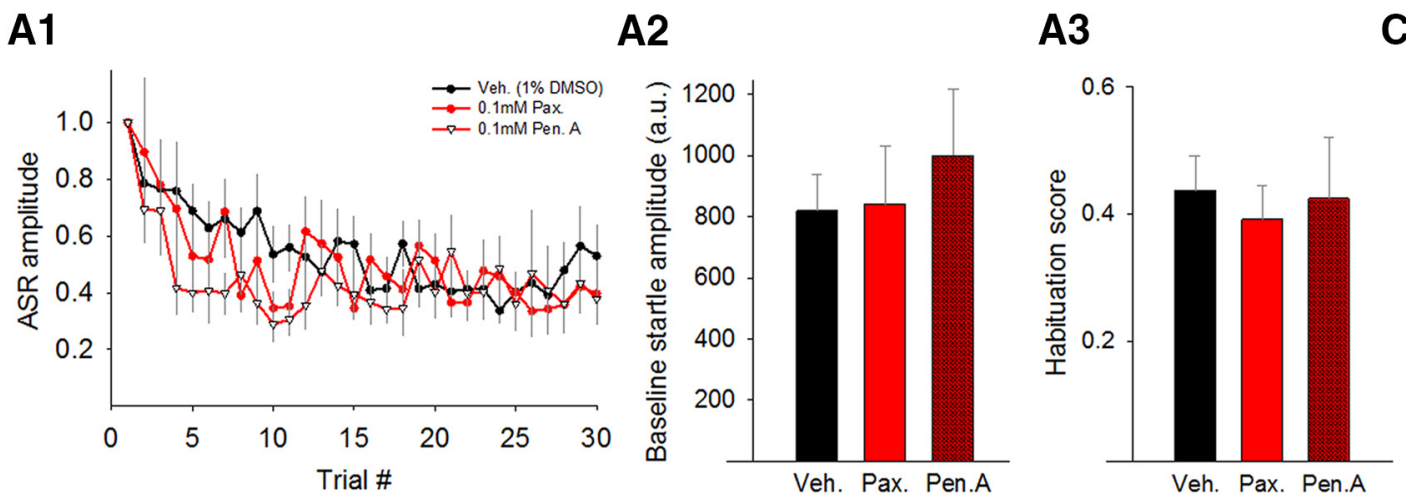

C

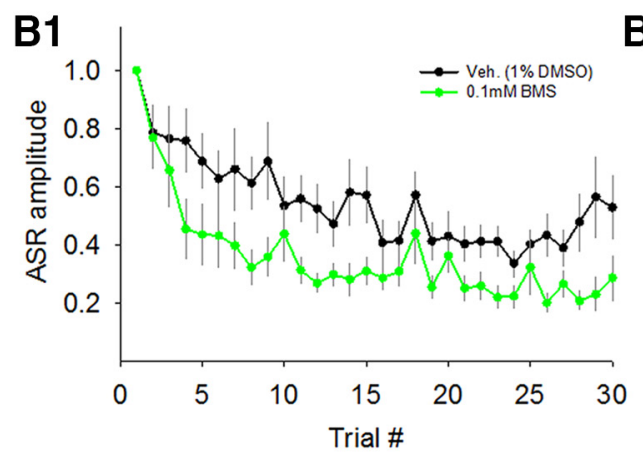

B2

B3
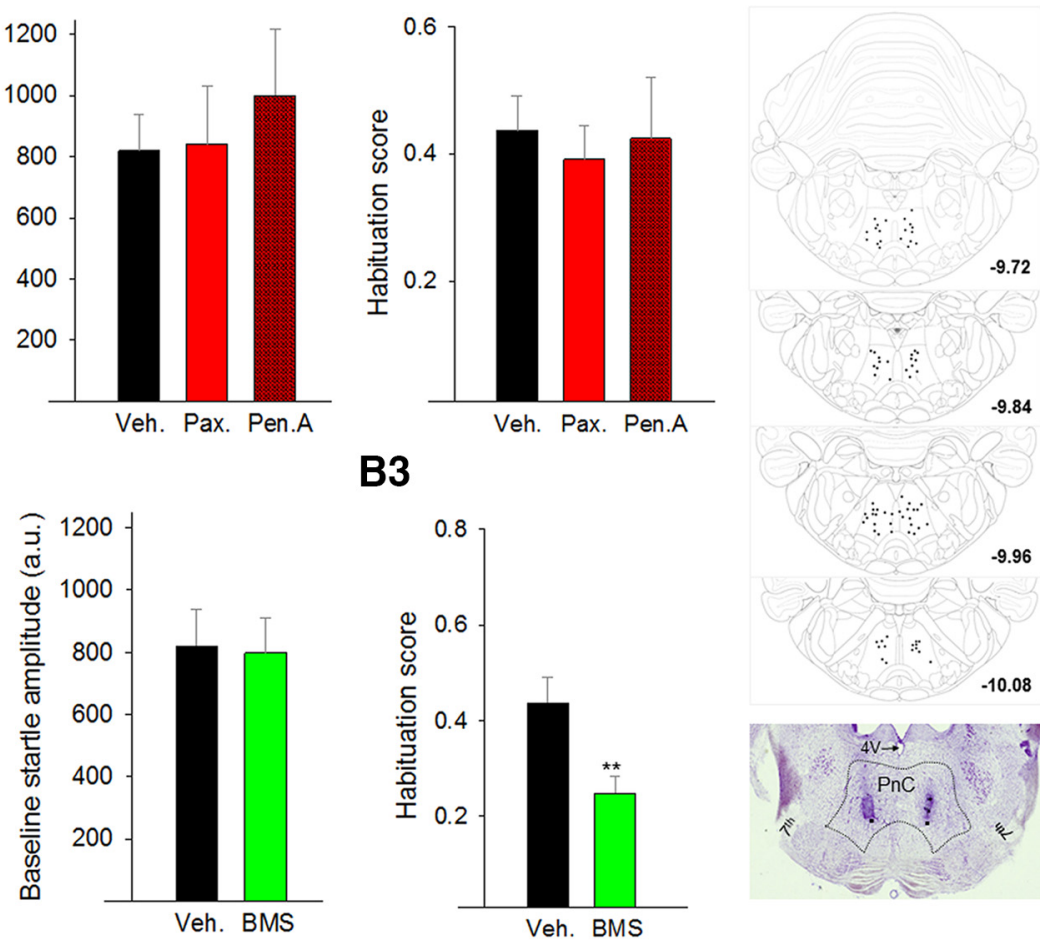

Figure 6. Modulation of BK channels in the PnC alters short-term habituation of ASR. A1, Short-term habituation of the ASR was not affected by local infusion of paxilline (0.1 mu, $p=0.437)$ or penitrem $\mathrm{A}(0.1 \mathrm{~mm}, p=0.226)$ into the $\mathrm{PnC}$ of rats. ASR amplitudes were normalized to the first startle response for each animal and then averaged across animals in each experimental group. $A 2$, Baseline ASR amplitudes were not affected by paxilline $(p=0.426)$ or penitrem A ( $p=0.912)$. A3, The habituation score (average of ASR amplitude trials 20 - 30 normalized to the amplitude of the first ASR) is also not affected by paxilline $(p=0.473)$ or penitrem $A(p=0.923)$. $A$, Paxilline: $n=11$; penitrem $A: n=9$ animals. $B 1$, Infusion of 0.1 mm BMS-204352 significantly enhanced short-term habituation $(p<0.001$ ). B2, Baseline ASR amplitude was not affected by BMS-204352 ( $p=0.877$ ). B3, The habituation score (see above) was significantly lower, indicating more habituation, after infusion of BMS-204352. ${ }^{* *} p=0.007$. C, Injection sites for drug microinfusions were verified postmortem, and only data with bilateral hits within the boundary of the PnC were included in the analysis. Each dot represents the tip of an injection cannula. Numbers indicate position from bregma ( $\mathrm{mm}$ ). Bottom, Exemplary slice is shown with the PnC outlined. The tip of each injector is marked with a dot. 4V, Fourth ventricle; seventh, seventh nerve.

C. elegans (Liu et al., 2007). Interestingly, a similar mechanism (i.e., the regulation of the BK channel contribution to afterhyperpolarization by CaMKII) has been shown in neurons of the vestibular nucleus (Nelson et al., 2005; van Welie and du Lac, 2011). Vestibular startle is the only startle modality that is not relayed through the PnC, but directly through the vestibulospinal tract (Yeomans et al., 2002), so it is intriguing to speculate that the same mechanisms in the $\mathrm{PnC}$ and in the vestibular nucleus lead to habituation of acoustic and vestibular startle, respectively.

\section{Experimental considerations}

One general consideration is the specificity of channel blockers/ openers used. Both paxilline and penitrem A are very potent blocker of BK channels with only some minor effects on the pH-sensitive slo-3 at higher doses (Zhang et al., 2006), and no effects on delayed rectifier $\mathrm{K}(+)$ currents, cloned voltagedependent Kv1.5 channels, or native ATP-dependent K(ATP) current (Asano et al., 2012). Likewise, BMS-204352 has been shown to be highly selective (Hewawasam et al., 2002) while having a minor effect on L-type calcium channels (Son et al., 2011).

One limitation of our study lies in the fact that only slices of 11- to 15 day-old animals could be used for the patch-clamp studies, due to increasing myelinization that impedes visual identification of PnC giant neurons in older animals. Acoustic startle responses can be earliest measured in vivo with the onset of hearing at postnatal days (PD) 12 and 13, when the meatus opens, and rats show habituation from this day on (Schmid et al., unpub- lished data). Synaptic depression measured in slices from PD15 rats (that show habituation) does not differ from synaptic depression in PD11 rat brain slices. Moreover, the wiring of auditory pathways has been shown to be functional already at PD 8 (Tokimoto et al., 1977), and studies addressing the tactile startle in developing rats revealed that these startle responses can be measured as early as PD 6 (Hickl et al., 1999). The tactile startle pathway converges with the auditory at the level of the PnC (Yeomans et al., 2002; Schmid et al., 2003), indicating that also the motor part of the startle pathway is established by that age. Last, our voltage-sensitive dye experiments confirmed that BK channeldependent depression as observed in PD11-P15 rat slices is also present in older rats.

Although this gives reason to assume that the startle pathway and habituation mechanisms are established as young as PD11-15, we cannot rule out that the age difference is responsible for the different effects of BK channel blocker and opener in the electrophysiological versus the behavioral studies on both baseline responses and synaptic depression/habituation. Likewise, differences in experimental temperature could have an impact on the activation kinetics and phosphorylation state of BK channels. Also, potential differences in effective concentration of drugs used in vivo versus in vitro could cause differential effects because it is impossible to control the effective concentration in vivo. These are all potential confounders and inherent challenges when combining different experimental approaches. Alternatively, it is possible that burst stimulation in the slice leads to a maximum activation of BK channels, creating a ceiling 
effect, so that the BK channel opener does not have any additional effect on the level of synaptic depression, whereas synaptic depression in vivo can be augmented. Accordingly, BK channel blockers were very efficient in blocking synaptic depression in the slice but failed to block habituation in vivo. This could imply that there might be different synapses that are only moderately depressed contributing to overall habituation, so that blocking depression at one place is compensated by parallel or downstream mechanisms. Furthermore, startle response amplitudes are always the sum of habituation and the parallel independent process of sensitization (Groves and Thompson, 1970; Rankin et al., 2009). While we tried to avoid sensitization in our behavioral experiments by using innocuous startle pulses and by extensive prior animal handling, one has to keep in mind that, in principle, any changes in habituation can be caused by altered sensitization.

In summary, there are a multitude of possible explanations why the results obtained in vivo and in vitro do not perfectly align, demonstrating the difficulties of directly relating in vitro electrophysiological data with behavioral studies in mammals. Nevertheless, all approaches clearly indicate the involvement of BK channel activation in habituation of startle.

\section{Mechanisms of habituation}

Neural mechanisms of habituation of startle or related escape responses have been studied in many different species such as C. elegans, Aplysia, Drosophila, zebrafish, and rodents. More detailed electrophysiological studies of the gill-withdrawal reflex in Aplysia revealed that short-term habituation is mediated, at least in part, by altered coupling of action potentials to transmitter release (Zhao and Klein, 2002); however, the molecular mechanism has not been determined to date. Activation/phosphorylation of BK channels might be the missing piece. On the other hand, burst stimulation of the presynaptic sensory neuron in the gill-withdrawal reflex pathway in Aplysia actually protects from synaptic depression (Wan et al., 2012), underlining the fact that stimulation paradigms in different pathways and/or animal models might trigger different effects (see also Fischer et al., 2014). Mutants with a BK channel knock-out in C. elegans (C. H. Rankin, personal communication), Drosophila (Engel and Wu, 1998), and mice (Typlt et al., 2013a) show disrupted short-term habituation of startle, supporting the results found in this study and indicating that startle habituation relies on a highly conserved BK channel-dependent mechanism across species (Schmid et al., 2010; Schmid et al., 2014). As much as habituation mechanisms are highly conserved, it also becomes increasingly apparent that there is not one single neuronal mechanism underlying behavioral habituation, but different mechanisms that contribute to the overall behavioral response, dependent on the sensory pathway studied, the time course of stimulation, and the behavioral/electrophysiological read out (Linster et al., 2009; Ramaswami, 2014; Marsden and Granato, 2015; Wolman et al., 2015; Pantoja et al., 2016).

\section{BK channel modulation as potential treatment}

Habituation of startle is disrupted in different mental disorders, most prominently in schizophrenia and autism spectrum disorders (Braff et al., 1992; Ornitz et al., 1993; Perry et al., 2007; Sinclair et al., 2016). We here show that habituation can be enhanced by positive BK channel modulation. Habituation as a sensory filtering mechanism is an essential process, shielding higher cognitive areas from the vast amounts of sensory information constantly relayed to the brain (Poon and Schmid, 2012). Disruptions in habituation are predictive for deficits in other cognitive function (Singer et al., 2013); thus, an enhancement of habituation in patient populations might have beneficial effects not only on hypersensitivity and hyposensitivity, but also on higher cognitive function.

BK channels are expressed abundantly in various brain regions of the mammalian brain, such as amygdala, caudate nucleus, cerebral cortex, hippocampus, hypothalamus, brainstem, and spinal cord (Tseng-Crank et al., 1994; Sausbier et al., 2006), as well as in the periphery. We here show a beneficial effect of BK channel modulators on habituation; however, we locally administered the drug into the specific brain region. A huge problem is the ubiquitous expression of BK channels and resulting off-target effects upon systemic administration of BK channel modulators (Nardi and Olesen, 2008; Bentzen et al., 2014). BK channel modulators have become a hot topic in pharmaceutical research as they are implicated in protection from reperfusion injury in the myocardium, in bladder function, as seizure medication, or as protection from neuronal excitotoxicity after stroke (for review, see Bentzen et al., 2014). To our knowledge, however, just one BK channel modulator has reached the stage of clinical studies to date, which is for anti-inflammatory treatment in patients with asthma (Malerba et al., 2015). More specific pharmacological tools are being developed that allow for modulation of specific BK channel subtypes (Yu et al., 2016). Future studies on ASR habituation will therefore have to use these new pharmacological tools as they become available, together with molecular and genetic analysis, to further decipher BK channel regulation and subtypes involved in synaptic depression underlying habituation, so that the underlying mechanisms can be targeted more specifically and through systemic drug administration. This will also allow for testing the impact of BK channel opener on other cognitive function.

\section{References}

Asano S, Bratz IN, Berwick ZC, Fancher IS, Tune JD, Dick GM (2012) Penitrem $\mathrm{A}$ as a tool for understanding the role of large conductance $\mathrm{Ca}(2+) /$ voltage-sensitive $\mathrm{K}(+)$ channels in vascular function. J Pharmacol Exp Ther 342:453-460. CrossRef Medline

Bentzen BH, Olesen SP, Ronn LC, Grunnet M (2014) BK channel activators and their therapeutic perspectives. Frontiers Physiol 5:389. CrossRef Medline

Bosch D, Schmid S (2006) Activation of muscarinic cholinergic receptors inhibits giant neurones in the caudal pontine reticular nucleus. Eur J Neurosci 24:1967-1975. CrossRef Medline

Bosch D, Schmid S (2008) Cholinergic mechanism underlying prepulse inhibition of the startle response in rats. Neuroscience 155:326-335. CrossRef Medline

Braff DL, Grillon C, Geyer MA (1992) Gating and habituation of the startle reflex in schizophrenic patients. Arch Gen Psychiatry 49:206-215. CrossRef Medline

Crane L, Goddard L, Pring L (2009) Sensory processing in adults with autism spectrum disorders. Autism 13:215-228. CrossRef Medline

Davis M (1984) The mammalian startle response. New York: Plenum.

Davis M, Gendelman PM (1977) Plasticity of the acoustic startle response in the acutely decerebrate rat. J Comp Physiol Psychol 91:549-563. CrossRef Medline

Davis M, Gendelman DS, Tischler MD, Gendelman PM (1982a) A primary acoustic startle circuit: lesion and stimulation studies. J Neurosci 2:791805. Medline

Davis M, Parisi T, Gendelman DS, Tischler M, Kehne JH (1982b) Habituation and sensitization of startle reflexes elicited electrically from the brainstem. Science 218:688-690. CrossRef Medline

Elison JT, Paterson SJ, Wolff JJ, Reznick JS, Sasson NJ, Gu H, Botteron KN, Dager SR, Estes AM, Evans AC, Gerig G, Hazlett HC, Schultz RT, Styner M, Zwaigenbaum L, Piven J (2013) White matter microstructure and atypical visual orienting in 7-month-olds at risk for autism. Am J Psychiatry 170:899-908. CrossRef Medline

Elsabbagh M, Fernandes J, Jane Webb S, Dawson G, Charman T, Johnson $\mathrm{MH}$ (2013) Disengagement of visual attention in infancy is associ- 
ated with emerging autism in toddlerhood. Biol Psychiatry 74:189-194. CrossRef Medline

Engel JE, Wu CF (1998) Genetic dissection of functional contributions of specific potassium channel subunits in habituation of an escape circuit in Drosophila. J Neurosci 18:2254-2267. Medline

Fischer TM, Jacobson DA, Demorest-Hayes K (2014) Network processes involved in the mediation of short-term habituation in Aplysia: contribution of intrinsic regulation of excitability and synaptic augmentation. Front Integr Neurosci 8:15. CrossRef Medline

Geis HR, Schmid S (2011) Glycine inhibits startle-mediating neurons in the caudal pontine reticular formation but is not involved in synaptic depression underlying short-term habituation of startle. Neurosci Res 71:114123. CrossRef Medline

Glanzman DL (2009) Habituation in Aplysia: the Cheshire cat of neurobiology. Neurobiol Learn Mem 92:147-154. CrossRef Medline

Gómez-Nieto R, Horta-Junior Jde A, Castellano O, Millian-Morell L, Rubio ME, López DE (2014) Origin and function of short-latency inputs to the neural substrates underlying the acoustic startle reflex. Front Neurosci 8:216. CrossRef Medline

Griguoli M, Sgritta M, Cherubini E (2016) Presynaptic BK channels control transmitter release: physiological relevance and potential therapeutic implications. J Physiol 594:3489-3500. CrossRef Medline

Groves PM, Thompson RF (1970) Habituation: a dual-process theory. Psychol Rev 77:419-450. CrossRef Medline

Hackney CM, Osen KK, Ottersen OP, Storm-Mathisen J, Manjaly G (1996) Immunocytochemical evidence that glutamate is a neurotransmitter in the cochlear nerve: a quantitative study in the guinea-pig anteroventral cochlear nucleus. Eur J Neurosci 8:79-91. CrossRef Medline

Hewawasam P, Erway M, Moon SL, Knipe J, Weiner H, Boissard CG, PostMunson DJ, Gao Q, Huang S, Gribkoff VK, Meanwell NA (2002) Synthesis and structure-activity relationships of 3-aryloxindoles: a new class of calcium-dependent, large conductance potassium (maxi-K) channel openers with neuroprotective properties. J Med Chem 45:1487-1499. CrossRef Medline

Hickl A, Pilz PK, Schnitzler HU (1999) The sensorimotor interface mediating the startle response is functional before the onset of hearing. In: Proceeding of the 1st Göttingen Conference of the German Neuroscience Society, p 809. Stuttgart: Thieme.

Hirstein W, Iversen P, Ramachandran VS (2001) Autonomic responses of autistic children to people and objects. Proc Biol Sci 268:1883-1888. CrossRef Medline

Hu H, Shao LR, Chavoshy S, Gu N, Trieb M, Behrens R, Laake P, Pongs O, Knaus HG, Ottersen OP, Storm JF (2001) Presynaptic $\mathrm{Ca}^{2+}$-activated $\mathrm{K}^{+}$channels in glutamatergic hippocampal terminals and their role in spike repolarization and regulation of transmitter release. J Neurosci 21: 9585-9597. Medline

Koch M (1999) The neurobiology of startle. Prog Neurobiol 59:107-128. CrossRef Medline

Lancaster B, Adams PR (1986) Calcium-dependent current generating the afterhyperpolarization of hippocampal neurons. J Neurophysiol 55: 1268-1282. Medline

Lang DG, Ritchie AK (1987) Large and small conductance calciumactivated potassium channels in the GH3 anterior pituitary cell line. Pflugers Arch 410:614-622. CrossRef Medline

Laumonnier F, Roger S, Guérin P, Molinari F, M'rad R, Cahard D, Belhadj A, Halayem M, Persico AM, Elia M, Romano V, Holbert S, Andres C, Chaabouni H, Colleaux L, Constant J, Le Guennec JY, Briault S (2006) Association of a functional deficit of the BKCa channel, a synaptic regulator of neuronal excitability, with autism and mental retardation. Am J Psychiatry 163:1622-1629. CrossRef Medline

Leekam SR, Nieto C, Libby SJ, Wing L, Gould J (2007) Describing the sensory abnormalities of children and adults with autism. J Autism Dev Disord 37:894-910. CrossRef Medline

Leitner DS, Powers AS, Hoffman HS (1980) The neural substrate of the startle response. Physiol Behav 25:291-297. CrossRef Medline

Lingenhöhl K, FriaufE (1992) Giant neurons in the caudal pontine reticular formation receive short latency acoustic input: an intracellular recording and HRP-study in the rat. J Comp Neurol 325:473-492. CrossRef Medline

Linster C, Menon AV, Singh CY, Wilson DA (2009) Odor-specific habituation arises from interaction of afferent synaptic adaptation and intrinsic synaptic potentiation in olfactory cortex. Learn Mem 16:452-459. CrossRef Medline

Liu Q, Chen B, Ge Q, Wang ZW (2007) Presynaptic $\mathrm{Ca}^{2+} /$ calmodulindependent protein kinase II modulates neurotransmitter release by activating BK channels at Caenorhabditis elegans neuromuscular junction. J Neurosci 27:10404-10413. CrossRef Medline

Malerba M, D Amato M, Radaeli A, Giacovelli G, Rovati L, Arshad SH, Holgate ST (2015) Efficacy of andolast in mild to moderate asthma: a randomized controlled, double-blind multicenter study (the Andast Trial). Curr Pharm Des 21:3835-3843. CrossRef Medline

Marsden KC, Granato M (2015) In vivo $\mathrm{Ca}(2+)$ imaging reveals that decreased dendritic excitability drives startle habituation. Cell Rep 13:17331740. CrossRef Medline

Martire M, Barrese V, D’Amico M, Iannotti FA, Pizzarelli R, Samengo I, Viggiano D, Ruth P, Cherubini E, Taglialatela M (2010) Pre-synaptic BK channels selectively control glutamate versus GABA release from cortical and hippocampal nerve terminals. J Neurochem 115:411-422. CrossRef Medline

Minshew NJ, Sweeney J, Luna B (2002) Autism as a selective disorder of complex information processing and underdevelopment of neocortical systems. Mol Psychiatry 7 [Suppl 2]:S14-S15.

Nardi A, Olesen SP (2008) BK channel modulators: a comprehensive overview. Curr Med Chem 15:1126-1146. CrossRef Medline

Narla C, Dunn HA, Ferguson SS, Poulter MO (2015) Suppression of piriform cortex activity in rat by corticotropin-releasing factor 1 and serotonin 2A/C receptors. Front Cell Neurosci 9:200. CrossRef Medline

Nelson AB, Gittis AH, du Lac S (2005) Decreases in CaMKII activity trigger persistent potentiation of intrinsic excitability in spontaneously firing vestibular nucleus neurons. Neuron 46:623-631. CrossRef Medline

Ornitz EM, Lane SJ, Sugiyama T, de Traversay J (1993) Startle modulation studies in autism. J Autism Dev Disord 23:619-637. CrossRef Medline

Pantoja C, Hoagland A, Carroll EC, Karalis V, Conner A, Isacoff EY (2016) Neuromodulatory regulation of behavioral individuality in zebrafish. Neuron 91:587-601. CrossRef Medline

Perry W, Minassian A, Lopez B, Maron L, Lincoln A (2007) Sensorimotor gating deficits in adults with autism. Biol Psychiatry 61:482-486. CrossRef Medline

Poon CS, Schmid S (2012) Non-associative learning. In: Encyclopedia of the sciences of learning (Seel NM, ed), pp 2475-2477. Heidelberg: Springer.

Poon CS, Young DL (2006) Nonassociative learning as gated neural integrator and differentiator in stimulus-response pathways. Behav Brain Funct 2:29. CrossRef Medline

Raffaelli G, Saviane C, Mohajerani MH, Pedarzani P, Cherubini E (2004) BK potassium channels control transmitter release at CA3-CA3 synapses in the rat hippocampus. J Physiol 557:147-157. CrossRef Medline

Ramaswami M (2014) Network plasticity in adaptive filtering and behavioral habituation. Neuron 82:1216-1229. CrossRef Medline

Rankin CH, Abrams T, Barry RJ, Bhatnagar S, Clayton DF, Colombo J, Coppola G, Geyer MA, Glanzman DL, Marsland S, McSweeney FK, Wilson DA, Wu CF, Thompson RF (2009) Habituation revisited: an updated and revised description of the behavioral characteristics of habituation. Neurobiol Learn Mem 92:135-138. CrossRef Medline

Robitaille R, Garcia ML, Kaczorowski GJ, Charlton MP (1993) Functional colocalization of calcium and calcium-gated potassium channels in control of transmitter release. Neuron 11:645-655. CrossRef Medline

Rokhlin OW, Guseva NV, Taghiyev AF, Glover RA, Cohen MB (2010) KN-93 inhibits androgen receptor activity and induces cell death irrespective of p53 and Akt status in prostate cancer. Cancer Biol Ther 9:224-235. CrossRef Medline

Sailer CA, Kaufmann WA, Kogler M, Chen L, Sausbier U, Ottersen OP, Ruth P, Shipston MJ, Knaus HG (2006) Immunolocalization of BK channels in hippocampal pyramidal neurons. Eur J Neurosci 24:442-454. CrossRef Medline

Sausbier M, Hu H, Arntz C, Feil S, Kamm S, Adelsberger H, Sausbier U, Sailer CA, Feil R, Hofmann F, Korth M, Shipston MJ, Knaus HG, Wolfer DP, Pedroarena CM, Storm JF, Ruth P (2004) Cerebellar ataxia and Purkinje cell dysfunction caused by $\mathrm{Ca}^{2+}$-activated $\mathrm{K}^{+}$channel deficiency. Proc Natl Acad Sci U S A 101:9474-9478. CrossRef Medline

Sausbier U, Sausbier M, Sailer CA, Arntz C, Knaus HG, Neuhuber W, Ruth P (2006) $\mathrm{Ca}^{2+}$-activated $\mathrm{K}^{+}$channels of the BK-type in the mouse brain. Histochem Cell Biol 125:725-741. CrossRef Medline

Schmid S, Simons NS, Schnitzler HU (2003) Cellular mechanisms of the 
trigeminally evoked startle response. Eur J Neurosci 17:1438-1444. CrossRef Medline

Schmid S, Brown T, Simons-Weidenmaier N, Weber M, Fendt M (2010) Group III metabotropic glutamate receptors inhibit startle-mediating giant neurons in the caudal pontine reticular nucleus but do not mediate synaptic depression/short-term habituation of startle. J Neurosci 30: 10422-10430. CrossRef Medline

Schmid S, Wilson DA, Rankin CH (2014) Habituation mechanisms and their importance for cognitive function. Front Integr Neurosci 8:97. CrossRef Medline

Schoen SA, Miller LJ, Brett-Green BA, Nielsen DM (2009) Physiological and behavioral differences in sensory processing: a comparison of children with autism spectrum disorder and sensory modulation disorder. Front Integr Neurosci 3:29. CrossRef Medline

Simons-Weidenmaier NS, Weber M, Plappert CF, Pilz PK, Schmid S (2006) Synaptic depression and short-term habituation are located in the sensory part of the mammalian startle pathway. BMC Neurosci 7:38. CrossRef Medline

Sinclair D, Oranje B, Razak KA, Siegel SJ, Schmid S (2016) Sensory processing in autism spectrum disorders and Fragile $\mathrm{X}$ syndrome: from the clinic to animal models. Neurosci Biobehav Rev. Advance online publication. Retrieved May 24, 2016. doi: 10.1016/j.neubiorev.2016.05.029. CrossRef Medline

Singer P, Hauser J, Llano Lopez L, Peleg-Raibstein D, Feldon J, Gargiulo PA, Yee BK (2013) Prepulse inhibition predicts working memory performance whilst startle habituation predicts spatial reference memory retention in C57BL/6 mice. Behav Brain Res 242:166-177. CrossRef Medline

Smith MA, Ashford ML (1998) Mode switching characterizes the activity of large conductance potassium channels recorded from rat cortical fused nerve terminals. J Physiol 513:733-747. CrossRef Medline

Son YK, Choi SW, Jung WK, Jo SH, Jung ID, Park YM, Choi IW, Sin JI, Shim EB, Kim N, Han J, Park WS (2011) The inhibitory effect of $\mathrm{Ca}^{2+}$. activated $\mathrm{K}^{+}$channel activator, BMS on L-type $\mathrm{Ca}^{2+}$ channels in rat ventricular myocytes. Life Sci 89:331-336. CrossRef Medline

Stroganova TA, Kozunov VV, Posikera IN, Galuta IA, Gratchev VV, Orekhova EV (2013) Abnormal pre-attentive arousal in young children with autism spectrum disorder contributes to their atypical auditory behavior: an ERP study. PLoS One 8:e69100. CrossRef Medline

Tian L, Coghill LS, MacDonald SH, Armstrong DL, Shipston MJ (2003) Leucine zipper domain targets cAMP-dependent protein kinase to mammalian BK channels. J Biol Chem 278:8669-8677. CrossRef Medline

Tokimoto T, Osako S, Matsuura S (1977) Development of auditory evoked cortical and brain stem responses during the early postnatal period in the rat. Osaka City Med J 23:141-153. Medline

Tseng-Crank J, Foster CD, Krause JD, Mertz R, Godinot N, DiChiara TJ, Reinhart PH (1994) Cloning, expression, and distribution of functionally distinct $\mathrm{Ca}(2+)$-activated $\mathrm{K}^{+}$channel isoforms from human brain. Neuron 13:1315-1330. CrossRef Medline
Typlt M, Mirkowski M, Azzopardi E, Ruth P, Pilz PK, Schmid S (2013a) Habituation of reflexive and motivated behavior in mice with deficient BK channel function. Front Integr Neurosci 7:79. CrossRef Medline

Typlt M, Mirkowski M, Azzopardi E, Ruettiger L, Ruth P, Schmid S (2013b) Mice with deficient BK channel function show impaired prepulse inhibition and spatial learning, but normal working and spatial reference memory. PLoS One 8:e81270. CrossRef Medline

Valsamis B, Schmid S (2011) Habituation and prepulse inhibition of acoustic startle in rodents. J Vis Exp 55:e3446. CrossRef Medline

van Welie I, du Lac S (2011) Bidirectional control of BK channel open probability by CAMKII and PKC in medial vestibular nucleus neurons. J Neurophysiol 105:1651-1659. CrossRef Medline

Wan Q, Jiang XY, Negroiu AM, Lu SG, McKay KS, Abrams TW (2012) Protein kinase $\mathrm{C}$ acts as a molecular detector of firing patterns to mediate sensory gating in Aplysia. Nat Neurosci 15:1144-1152. CrossRef Medline

Wang ZW (2008) Regulation of synaptic transmission by presynaptic CaMKII and BK channels. Mol Neurobiol 38:153-166. CrossRef Medline

Weber M, Schnitzler HU, Schmid S (2002) Synaptic plasticity in the acoustic startle pathway: the neuronal basis for short-term habituation? Eur J Neurosci 16:1325-1332. CrossRef Medline

Wolman MA, Jain RA, Marsden KC, Bell H, Skinner J, Hayer KE, Hogenesch JB, Granato M (2015) A genome-wide screen identifies PAPP-AAmediated IGFR signaling as a novel regulator of habituation learning. Neuron 85:1200-1211. CrossRef Medline

Womack MD, Khodakhah K (2003) Somatic and dendritic small-conductance calcium-activated potassium channels regulate the output of cerebellar purkinje neurons. J Neurosci 23:2600-2607. Medline

Yeomans JS, Li L, Scott BW, Frankland PW (2002) Tactile, acoustic and vestibular systems sum to elicit the startle reflex. Neurosci Biobehav Rev 26:1-11. CrossRef Medline

Yu M, Liu SL, Sun PB, Pan H, Tian CL, Zhang LH (2016) Peptide toxins and small-molecule blockers of BK channels. Acta Pharmacol Sin 37:56-66. CrossRef Medline

Zhang X, Zeng X, Lingle CJ (2006) Slo3 $\mathrm{K}^{+}$channels: voltage and $\mathrm{pH}$ dependence of macroscopic currents. J Gen Physiol 128:317-336. CrossRef Medline

Zhao Y, Klein M (2002) Modulation of the readily releasable pool of transmitter and of excitation-secretion coupling by activity and by serotonin at Aplysia sensorimotor synapses in culture. J Neurosci 22:10671-10679. Medline

Zhou J, Nannapaneni N, Shore S (2007) Vessicular glutamate transporters 1 and 2 are differentially associated with auditory nerve and spinal trigeminal inputs to the cochlear nucleus. J Comp Neurol 500:777-787. CrossRef Medline

Zwaigenbaum L, Bryson S, Rogers T, Roberts W, Brian J, Szatmari P (2005) Behavioral manifestations of autism in the first year of life. Int J Dev Neurosci 23:143-152. CrossRef Medline 